University of Louisville

ThinkIR: The University of Louisville's Institutional Repository

Electronic Theses and Dissertations

$12-2019$

\title{
Towards a theory of human mobility and wall-building: a comparative analysis of Hadrian's Wall and the Iron Curtain.
}

Timothy Heine

University of Louisville

Follow this and additional works at: https://ir.library.louisville.edu/etd

Part of the Social and Cultural Anthropology Commons

\section{Recommended Citation}

Heine, Timothy, "Towards a theory of human mobility and wall-building: a comparative analysis of Hadrian's Wall and the Iron Curtain." (2019). Electronic Theses and Dissertations. Paper 3397.

https://doi.org/10.18297/etd/3397

This Master's Thesis is brought to you for free and open access by ThinkIR: The University of Louisville's Institutional Repository. It has been accepted for inclusion in Electronic Theses and Dissertations by an authorized administrator of ThinkIR: The University of Louisville's Institutional Repository. This title appears here courtesy of the author, who has retained all other copyrights. For more information, please contact thinkir@louisville.edu. 


\section{TOWARDS A THEORY OF HUMAN MOBILITY AND WALL-BUILDING: \\ A COMPARATIVE ANALYSIS OF \\ HADRIAN'S WALL AND THE IRON CURTAIN}

\section{By}

Timothy Heine

A Thesis Submitted to the Faculty of the College of Arts \& Sciences

University of Louis ville for the Degree of

Master of Arts Anthropology

Department of Anthropology

University of Louis ville

Louisville, Kentucky

December 2019 



\section{TOWARDS A THEORY OF HUMAN MOBILITY AND WALL-BUILDING: \\ A COMPARATIVE ANALYSIS OF \\ HADRIAN'S WALL AND THE IRON CURTAIN}

$$
\text { By }
$$

Timothy Heine

BS, University of Kentucky, 1983

MD, University of Louis ville, 1988

A Thesis Approved on

August 12, 2019

by the following Thesis Committee:

\begin{tabular}{c}
\hline Julie Peteet, PhD \\
Thesis Advisor \\
\hline Christopher Tillquist, $\mathrm{PhD}$ \\
Committee Member \\
\\
\hline Margath Walker, PhD \\
Committee Member
\end{tabular}




\section{ACKNOWLEDGMENTS}

To Julie Peteet, $\mathrm{PhD}$, for her generous guidance in assisting me to organize my thoughts on humans and their proclivity to build walls, as well as for her steadfast push to rid my thesis of the dreaded run-on sentence, semi-colon and em dash.

To Christopher Tillquist, $\mathrm{PhD}$, for his enthusiastic welcome into the MA program more than five years ago, as well as for his steadfast support of a non-traditional student scratching a later-in-life academic itch.

To Julie, Christopher, Shawn Parkhurst, PhD, Jonathan Haws, PhD, Fabian Crespo, $\mathrm{PhD}$ and Jennifer Westerfeld, $\mathrm{PhD}$ for teaching seminars over the last several years that were thoughtfully organized, well taught and engaging.

To Maggie Walker, $\mathrm{PhD}$, for agreeing (without any apparent hesitation) to serve as an extradepartmental member of this thesis committee.

To my fellow (and significantly more youthful) graduate students, for rekindling my hope for the future through their curiosity and earnestness.

To the University of Louisville and its Department of Anthropology, for providing a high-quality graduate program with top-notch standards and impressive academic rigor.

And, most of all, to my wife, Caroline, for her unceasing encouragement to think deeply. In addition, by virtue of her uncanny editorial abilities and focus on verb tense matching, my writing was is considerably enhanced. 


\section{ABSTRACT \\ TOWARDS A THEORY OF HUMAN MOBILITY AND WALL-BUILDING: A COMPARATIVE ANALYSIS OF HADRIAN'S WALL AND THE IRON CURTAIN}

Timothy Heine, MD

December 13, 2019

This thesis contributes a theory on human bordering practices that encompasses diverse types of borders and border experiences. In order to flesh out the factors underlying human wall-building, it is vital to first understand the mobile nature (both as an innate characteristic and adaptive strategy) of our species. A clearer appreciation of the biology of human mobility elucidates the seemingly counterintuitive process of the establishment of cultural boundaries. Such an inquiry into the available inter-disciplinary literature on the topics of human mobility and wall-building reveals much about the manner in which humans interpret and utilize space, the variety of walls that exist, and the ways in which varying boundary types are imagined, constructed and managed as social institutions. In addition, this analysis provides insights into the frontier boundaries created peripheral to, or, on either side of, physical and ideological (or non-material) borders, as well as how such barriers, despite an intent to distinguish and separate populations, paradoxically create zones that allow for a more efficient integration and fusion of these populations. In this way, borders serve vital integrative roles in such transitional spaces. 
Previous analysis and discussion of such behaviors tends to focus on single variables that are at the root of the human propensity to build boundaries. A multidisciplinary review of the literature dealing with the construction of human walls over both lengthy temporal and varied typological continua creates an opportunity to concisely articulate an original, multifactorial general theory of human wall-building that is consistent across a diversity of wall-building projects. The S-ential Theory of Human WallBuilding describes the essential elements - separation, structure, social skin, symbolism and societal status quo - that, to varying degrees, drive humans to construct both physical and ideological barriers. With this theory in hand, the reader can better understand the connections between the past and present and, thus, more clearly comprehend and discuss issues pertaining to contemporary and future wall-building projects.

Using the S-ential Theory as a tool to more clearly appreciate the end-result of human wall-building, this review then explores a comparative analysis of two historical walls - the Roman Empire's $2^{\text {nd }}$ century Hadrian's Wall that traversed the entire breadth of the Britannian isthmus and the mid-20 $0^{\text {th }}$ century Iron Curtain that served as an imposing ideological barricade between Eastern and Western Europe for nearly five decades. These two walls, analyzed because of their particular locations at disparate ends of temporal and typological continua, allow for a critical inquiry into human wall-building across both an expanse of time and differing taxonomies. An analysis of these distinct wall classifications, through the lens of available interdisciplinary material on the origins of human mobility and wall-building, challenges the reader to think more critically about the nature, consistencies and dissimilarities of the component threads woven into the boundless tapestry of human bordering practices. 


\section{TABLE OF CONTENTS}

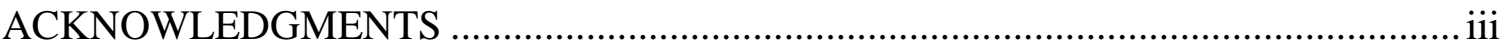

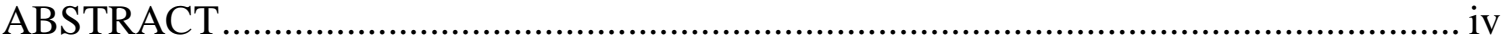

CHAPTER 1 - INTRODUCTION

HUMAN MOBILITY AND W ALL-BUILDING - CONNECTING THE DOTS ................................. 1

HUMAN WALLS - ARTICULATING A NEW GENERAL THEORY ......................................... 4

\section{CHAPTER 2 - LITERATURE REVIEW}

Human Mobility - Early Human MOVEMEnT AND Migratory PatTERnS .............. 8

DEMOGRAPHIC AND ENVIRONMENTAL DRIVERS OF HUMAN MIGRATION........................ 10

BUILDING WALLS - FEAR MANAGEMENT AND OTHERING …………………................ 14

CULtuRAL AND Cognitive Co-Evolution …………............................................ 17

TERRITORIAL COMPARTMENTALIZATION AND W ALLS AS SOCIAL CONSTRUCTIONS ..... 21

THE EXPRESSION OF POWER, THE DOCILE BODY AND SPATIAL PRACTICES ..................... 30

The Production of Mobilities - Mobility, SPACE And Power …………………..... 35

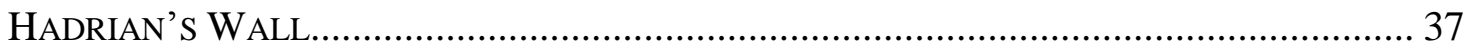

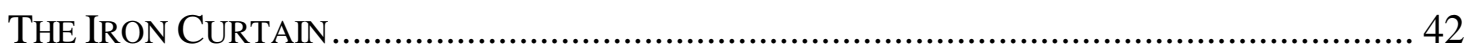

\section{CHAPTER 3 - SYNTHESIS}

HUMAN MOBILITY AND THE NATURE OF BORDERS ……………………………...... 48

THE S-ENTIAL THEORY OF HUMAN WALL-BUILDING ................................................. 51

THE S-ENTIAL THEORY - DISCUSSING THE FIVE S'S .................................................52

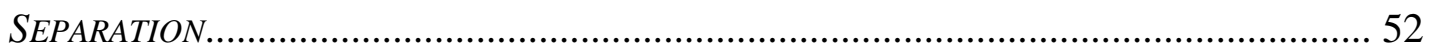

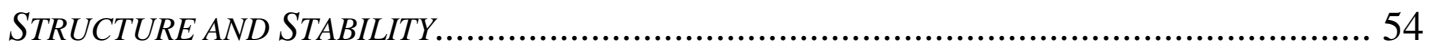

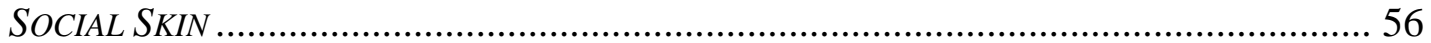

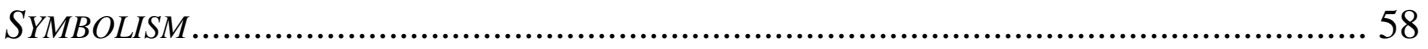

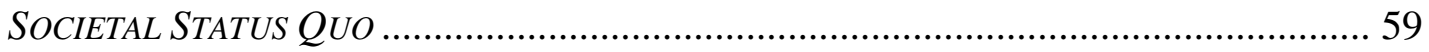

A COMPARATIVE ANALYSIS OF Two DisTINCT WALLS.................................................. 60

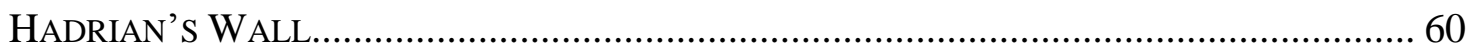

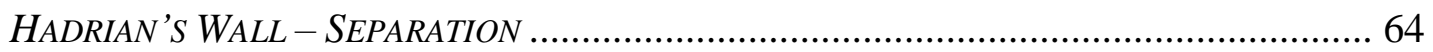

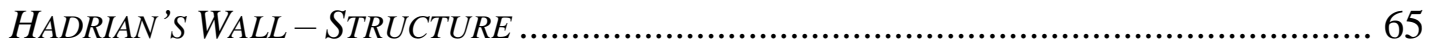

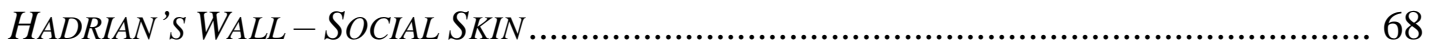

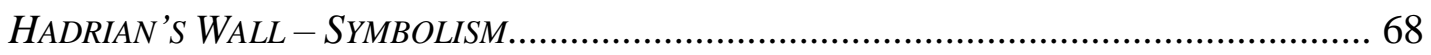

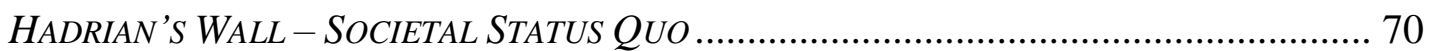

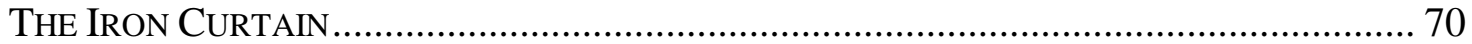

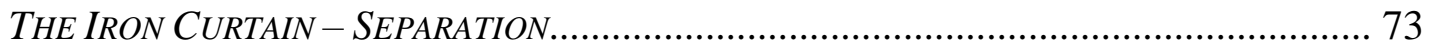

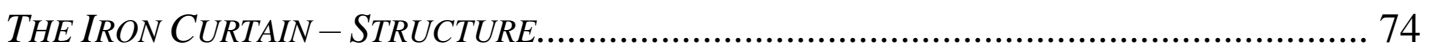

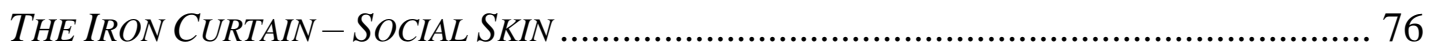

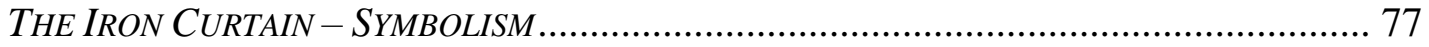


THE IRON CURTAIN - SOCIETAL STATUS QUO

CHAPTER 4 - CONCLUSION

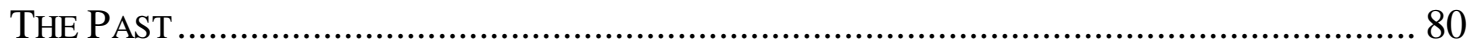

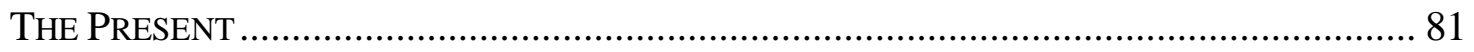

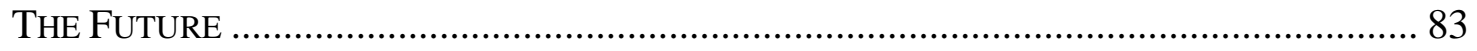

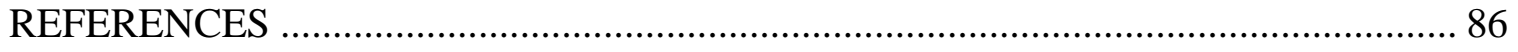

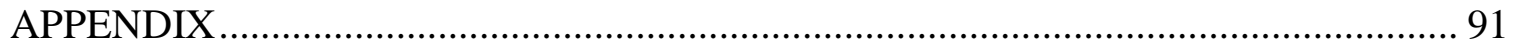

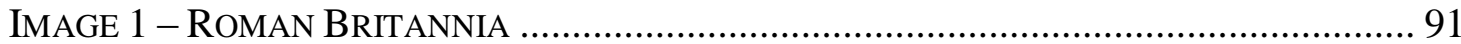

IMAGE 2 - ROUTE OF HADRIAN'S WALL .................................................................. 92

IMAGE 3 - CROSS SECTION SCHEMATIC ANALYSIS OF HADRIAN'S WALL...................... 93

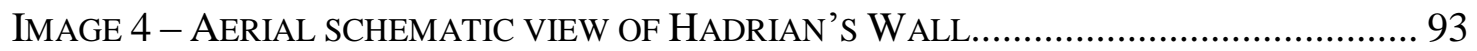

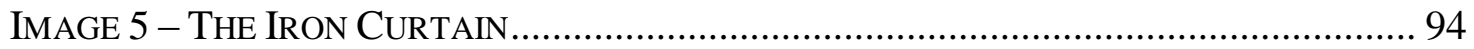

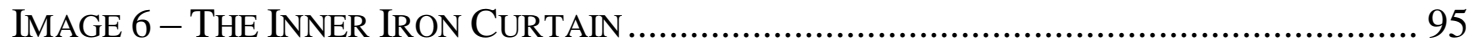

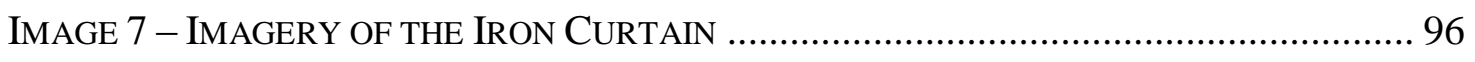

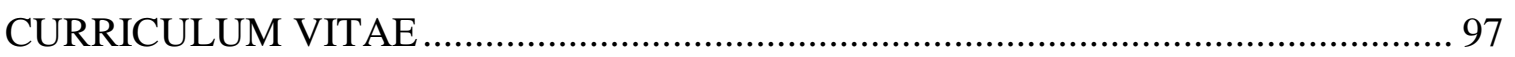




\section{CHAPTER 1 - INTRODUCTION}

\section{Human MoBILITY AND WALL-BuILDING - CONNECTING THE DotS}

Walls have been ubiquitous fixtures upon the human landscape for thousands of years. Early scaled structures were built around domesticated fields in the Levant, Etruscan villages, Irish grazing fields, and age-old Coptic Christian monasteries of Egypt. More substantial barriers are seen at the sites of Greek city-states, Tuscan hill towns, and the Croatian Walls of Ston. In addition, behemoth constructions such as Hadrian's Wall in England, the Walls of Troy and the Sumerian Amorite Wall are also remnants of the distant past. More recently, the Berlin Wall, the now-fallen, structural icon of Communist Europe (and its ideological, non-material component, the Iron Curtain), the West Bank Wall snaking across a fractious Palestine and the border emerging at the United States' southern boundary with Mexico, ostensibly, are similarly envisioned and fabricated as a means to control the flow of humans, goods and ideologies. In order to thoroughly appreciate the breadth of human wall-building, it seems prudent to delve into the reasoning at the foundations of such barriers.

Humans have long undertaken wall-building of various sorts for myriad reasons. ${ }^{1}$ While it seems safe to assume that providing an impediment to movement, in and of itself, would be a worthy goal of wall-building for a multitude of reasons (for example, managing

\footnotetext{
${ }^{1}$ Arguably, the earliest known Homo-built structure is located at Bruniquel Cave in southwestern France dating back some 175,000 years BCE. The cave's inner walls are thought to have been constructed in order to assist in providing illumination by fire to the interior chambers of the cave. (Jaubert 2016).
} 
one's fear of vicious animals or violent human neighbors, defending one's family, home and property, safeguarding limited or valuable resources, sending a simple, clear message that "this is mine!", maintaining cultural, political or religious homogeneity, bringing additional structure to a chaotic environment, establishing communal polity, more clearly demarcating and mapping territorial boundaries, preventing the spread of miasma and disease, or, perhaps, more optimally allocating labor pools, intellectual assets and financial capital) care must be taken in adopting such assumptions. It is a challenging leap to make inferences about the human species and its reasoning behind building walls without, first, having a deeper comprehension of the prolonged history behind its apparent need for walled boundaries.

Whether constructed to contain the flow of people, define the transition from a public zone to a private one, or generate cultural messaging through symbolic representation, walls have played, and continue to play, seminal roles in societies and cultures throughout our world. In order to further understand the motivations behind the human construction of walls, numerous questions ought to be considered. Among these questions: What are the catalysts that propel humans to imagine walls? What is the nature of human mobility? Is mobility innate and, if so, why has our species placed barriers that slow or cease our abilities to move ourselves, our goods and our ideologies? What forms, from the rudimentary to the more complex, have walls assumed in the past? What are the sociological and cultural contexts within which specific walls are conceptualized and fabricated? Are there persistent thematic threads that underlie the diverse origins of walls? And, is the building of physical walls connected with the building of ideological or non- 
material walls? An interdisciplinary approach to mobility and wall-building illuminates the common links among these human endeavors across temporal and typological spans.

Based upon a close reading of the research on mobility and walls, this thesis also asks: Why are walls so prevalent and what is the essence of their functionality? What are the common threads responsible for consistently driving humanity to construct such a panoply of walls? Furthermore, once built, what effects do walls have beyond their physical and ideological existence? That is, apart from their ability to hinder the flow of movement or ideology, what vital sociocultural and symbolic roles do such barriers play in the human experience? Once an understanding of wall-building is more fully ascertained and a general theory described, walls can then be used as a lens through which general assumptions regarding this aspect of human nature might be more appropriately formulated and understood. The story of human mobility, from ancient migratory pathways to more recent wall-building projects, has been well marked by our innate tendencies to both widely roam and to conceive physical and ideological boundaries. Intuitively, it would seem that unhindered mobility and the demarcation of boundaries (those places where human movement must slow and proceed with caution, or, rather, cease all together) co-exist at different ends of the spectrum that effectuates the spatial and temporal translocation of people and their cultures. To more fully fathom these seemingly contrasting attributes, a nuanced appreciation of their origins, intersections and disparities is in order.

Even for those who remain relatively immobile throughout their lives, the ideas and realities of bordering have broad implications. Beyond the corporeal reality of blocking, contrivances built to separate are rich in extracorporeal symbolism. From an embodiment of the state's legitimate monopolization of structural violence and the control of movement, 
to being appropriated as exclusionary gateways and toll booths, to controlling and stratifying temporal dimensions, to creating spaces of displacement, to speaking through media, signage and lexicon, and to their effects on humanitarianism, advocacy and neutrality, walls affect all of us in countless ways. This human quality to demarcate space, I argue, emanates from evolutionary traits acquired over many millennia. As such, it is relevant to seek evidence of building blocks in the human neuro-biological and cognitive make-up that apply to such a nature and how these traits are expressed in the construction and management of physical and ideological barriers.

This analysis looks at literature that supports and/or questions the uniqueness of human mobility and wall-building capacities. Issues such as tribalism, social cohesiveness and geopolitical strategy, for example, and how these issues relate to the human demarcation of boundaries are discussed. Ultimately, this inquiry provides insights into the historical, archaeological, neuro-biological, cognitive and cultural origins that underpin, facilitate and drive the imagining and construction of walls as juxtaposed to the natural disposition of human mobility. Therefore, an analysis of walls of varying types across a temporal span, from ancient Hadrian's Wall to the modern, ideological barrier, the Iron Curtain, and their connection to the ancient human proclivity to move will allow a keener discernment of the expressions of the complex, multifactorial and deeply-rooted human drive to erect walls.

\section{Human Walls - Articulating a NeW General TheORY}

Furthering existent research, this thesis develops and promotes a novel theory of bordering, the S-ential Theory of Human Wall-Building, that encompasses diverse types of borders and boundary experiences across an elongated sweep of time. One of the goals of 
this project is to take two relatively complex topics (human mobility and boundarybuilding) and distill the available material on these subjects into an original theory of wallbuilding that is accessible to both academic and non-academic audiences. An exploration of the literature informs the readership about human mobility, the co-evolution of cognition and culture, the intersections of human mobility and human walls, the behaviors that underlie the conception and development of human walls, and the ways in which varying boundary types are devised and utilized as social institutions. In addition, this analysis provides insights into the frontier boundaries created peripheral to physical and ideological borders and how such peripheral zones of differentiation create hybridized populations and cultures that serve vital roles in transitional spaces.

Thus, this thesis develops a lens through which the origins of both human mobility and wall-building can be more clearly appreciated. An interdisciplinary lens provides differing viewpoints that enrich the crafting of a comprehensive analytical framework. In this light, the literature review introduces topics from human migration and fearmanagement strategies to the implications of changing landscapes on individuals and societies. In addition, the production and control of mobility, space, time and power, as well as border making at the nation-state level, and the role of geopolitics and geopolitical strategy in the formation and maintenance of ancient and contemporary borders are also recognized. Through such a many-faceted lens, this project assesses the representational significance of material and ideological walls over an extended period of time. This project's literature review explores the integrative ethnographic and secondary literature that describe the foundational elements of human mobility and human wall-building across a wide swath of time. The literary and video sources supporting the review and its 
subsequent analysis are derived primarily from the following sources: various University of Louisville University Libraries data bases, the Google Scholar data base, and scholarly articles and books.

The construction of physical and ideological walls (those barriers to the flow of human ideology and culture) is a process riddled with age-old consequences, symbolism and innuendo, making its study of compelling interest. Certainly, the topic is complex, but a more distinct understanding of the effects that wall-building has had in the past, and continues to have on the present, is a goal worthy of further study, analysis and commentary. Processing such an inquiry ultimately allows for the formulation and eventual description of a multi-factorial theory of human wall-building. This new theory, the $S$ ential Theory of Human Wall-Building, provides an opportunity to more fully appreciate the breadth and convoluted interrelation of human practices underlying the construction of borders. As this analysis reveals, humans build walls to satisfy a number of needs: to separate, create structure, impart symbolic messaging, provide points of social interfacing and reify status quos. These needs rarely, if ever, exist as sole determinants in wallbuilding. Rather, each of these individual factors plays a varying role in the complex decision-making that exists as walls are conceived and constructed.

Once this theory is described in Chapter 3, a comparative analysis of physical and ideological walls at disparate ends of a temporal spectrum is undertaken in order to assess the validity of the theory. This chapter supports the comparative analysis of these two historical walls: the Roman Empire's $2^{\text {nd }}$ century Hadrian's Wall that traversed the breadth of the Britannian isthmus and the mid-20 ${ }^{\text {th }}$ century Iron Curtain, once an imposing ideological barricade between Eastern and Western Europe. Via this analysis, The S-ential 
Theory of Human Wall-Building is substantiated as each of its basic five tenets are tested as being applicable to both of these border projects. 


\section{CHAPTER 2 - LITERATURE REVIEW}

\section{Human Mobility - Early Human Movement And Migratory Patterns}

To be a human being in the true sense of the word, one has to be unsettled.

Vilém Flusser (2003)

Prior to gleaning a deeper understanding of the human propensity to construct walls, one must begin with a fuller appreciation of our desire to wander, as the former places obstacles in the path of the latter. With this is mind, the literature review discusses topics relevant to these issues, commencing with mobility and segueing into the construction of barriers. To begin the conversation of the relationships of these materials with one another, one must first go far back in time. The paleoanthropological literature is replete with a cache of information regarding hominin ancestry and provides a relevant point of departure. The large-scale implications of the pre-hominin transition from forest to savannah several million years ago, and, subsequently, the more expansive migratory movements out of Africa onto and throughout the Asian and European continents (and beyond) are becoming increasingly well illustrated. As humans and their hominin ancestors have moved about over the deep expanse of time, they have taken their evolving cognitive capabilities, cultures, and beliefs with them. Therefore, in order to understand walls, we must first explore human mobility.

Though the argument may be somewhat of a chicken and egg causality dilemma, the idea that fundamental changes in cranial capacity of early Homo species such as Homo 
erectus are important in forcing early human ancestors to become more mobile is widely accepted. In either case, as an enlarging brain requires increasing amounts of fuel to function efficiently, early humans, some 1.5-2.5 Ma, are forced to forge ahead in the pursuit of a diet richer in caloric content - especially meat-based sustenance. While early humans fare poorly in short-distance sprints against predators, their hunting and scavenging are well served by their capacity for slower, sustained long-distance movement. According to evolutionary psychologist Thomas Suddendorf, it is no coincidence that around this period of time Homo erectus begins to develop "distinct adaptive advantages" including a "new degree of behavioral flexibility... open-ended, reflective mental-scenario building and connecting of minds" (Suddendorf, 252). Some combination of increasing cognitive capabilities and the brain's physiologic need for fuel, as well as regional demographic pressures, set the stage for early ancestral requirements for scavenging and hunting over larger and larger areas.

The road-mapping of events around the movement(s) of Homo sapiens out of Africa some $75-150 \mathrm{ka}$ is being steadily reified. We do understand that abrupt changes in climate occurred. As a consequence, large swaths of temperate Africa likely became unsuitable to sustain the carrying-capacity necessary for large human settlement, thus forcing those exposed to significant demographic and environmental stressors to move farther afield. These groups, along with their expanding cognitive and cultural armaments, would form the initial founder populations of the Eurasian continent. The importance of coastal migration (with its steady provision of food resources, such as fish, shellfish, mammals, and fresh water) as a key ingredient to human migratory patterns was at first conjectured but is now more firmly supported. Amanuel Beyin (2015), an anthropologist 
whose work is focused on the migration routes of early modern humans, and Paul Mellars (2006), a British archaeologist with a keen interest in Neanderthal behavioral patterns, note that a southern route, across the Strait of Bab al Mandab onto the Arabian Peninsula, and a northern route along the Red Sea's western coast and up through the Nile Valley and Sinai Peninsula into the Levant, are probable primary conduits for early modern humans migrating out of Africa into southwestern Asia.

\section{DEMOGRAPHIC AND ENVIRONMENTAL DRIVERS OF HUMAN MIGRATION}

Once considered a rather linear, step-wise journey out of the continent, the story of early humans leaving Africa to colonize the globe has become more intricately outlined. As anthropologist Susan Antón and paleontologist Carl Swisher (2004) discuss, it is becoming increasingly clear that early human ancestors moved into Eurasia in fits-andstarts (that is, there were legion movements of multiple Homo species moving out of, and perhaps on occasion back into, Africa) as early as 1.8 Ma. This resulted in different Homo species co-existing alongside one another in the distant past to the point of, at times, presenting opportunities for interbreeding. While, for example, the presence of Homo erectus is seen on the Eurasian land mass in the early Pleistocene, members of this species also remained behind in Africa where they appear to have developed the earliest controlled use of fire, subsequently passing this cultural innovation to their Homo sapiens descendants. Mary Stiner (2002) notes that hominids thinly populated the breadth of southern Eurasia as early as $1.7 \mathrm{Ma}$, to be eventually followed by modern Homo sapiens (with both groups possibly utilizing multiple routes out of Africa.) According to Stiner, whose work spotlights early human social evolution, it was Homo sapiens that eventually made the journey off the African continent into Eurasia, quickly spread throughout the 
Eurasian land mass, and, ultimately, flourished. As outlined by archaeologist Peter Bellwood (2013), Homo dispersal specialist Susan Antón (2004) and Chinese researcher DongJu Zhang (2016), for a variety of reasons (cognitive disadvantage, climate mismatch, population pressures, paucity of resources and tribal imperialism, as several examples) the other Eurasian Homo species floundered and eventually failed, leaving their trail only in fossils, archaeological remnants and residual DNA.

Yet, as we more clearly come to grasp with early human migration, the rationale underlying such patterns of mobility must, too, be further dissected. Over the past several million years, a substantial part of Earth underwent long-term climatic fluctuations characterized by the significant accumulation and contraction of glacial ice - glacial and interglacial periods. The seesawing effect of temperature swings was not particularly amenable to stable evolutionary processes amongst pre-humans, especially in the highest and lowest latitudes. On the other hand, tropical zones, like those found on the African continent, were relatively stable incubators for evolving hominins, and findings of bountiful archaeological and fossil remnants support the position that the Homo species found its origins here (Beyin 2015). The African continent, too, is considered the root of modern human cultural innovation, as rudimentary tool-making is found here as early as 2 Ma acknowledging the evolving early human abilities of “... planning and social communities that can facilitate retention and transmission of technical skills" (Ibid.: 4-5).

Pre-historic human migration, from a mile-high strategic viewpoint, has been driven by survival. Unique in their ability to migrate and adapt to every region of the world, humans and their ancient forebears have kept moving in order to acquire the nutriments and other resources necessary for survival, locate and claim additional territory, escape 
competing populations or flee inhospitable environments (Bellwood 2013). Migration has served to give human populations additional opportunities for survival, while at the same time stimulating biological and social diversity as populations intermix under the influences of natural biological and cultural selective processes. Arguing for movement as an innate, natural state, Bellwood notes that "an ability and a propensity to migrate over large distances have always been defining features of our human species...” (Ibid.: 1).

In their analysis of human deep history, anthropologist Andrew Shryock and colleagues (2011) are clear in articulating human migration as "one of the fundamental processes in human history" involving complex algorithms of dispersal, displacement and diaspora (Shryock,192). In addition, the authors discuss the important interplay of demographic and climatic stressors at the root of large migratory patterns of the past, as well as the biological and social modifications and adaptations that allowed early human populations to succeed in their slow and steady, albeit not always stable, journey into new territories. [In a fascinating computational model, geographer and historian Jared Diamond (1997) translates the power of compounding population growth and rate of movement into numbers that highlight the potential of humans to fill a space and, as a result, relatively quickly amplify local carrying-capacity pressures. Using the example of the Clovis people of North, Central and South America, Diamond states that with a conservative population growth rate of $1.1 \%$ and average migration of 8 miles annually, an American founder population of one hundred individuals would fill the entirety of the American land mass with ten million people in a mere one thousand years (Diamond, 45).] While the stimulus for vast spatial migration seems uniquely innate to our species, as "[the human] taste for mobility stands in sharp contrast to the sedentary ways of many other animals... [as] our 
closest living [primate] relatives generally occupy small, circumscribed home ranges or territories" (Shryock, 199), the foundation of boundary building does not. Instead, with the evolution of human social systems, boundary making culturally evolves as the bedrock of a "process of urbanization" reflecting "marked differences in geography, culture and local histories" (Ibid.: 254).

Over a period of tens of thousands of years, as they gradually gain foothold, the Eurasian founder populations slowly and inexorably continue to move onward following migratory routes into the central Eurasian steppes, European continent proper, Indian subcontinent and southeastern Asia. With them, they take increasingly sophisticated material goods and other cultural practices - as evidenced by findings of progressively refined tools, vessels, beads, clothing, housing and funerary practices (Mellars 2006). To add even more value to the understanding of the intersection of mobility, culture and boundary building, studies of human migratory patterns into the Tibetan Plateau some 3.5$15 \mathrm{ka}$ and their effects on the development of agriculture and agriculture-based political economies further refine the concept of expanding human colonialization resulting not only in the acquisition of new (if not virgin) territory, but also in the creation of uniquely blended cultures as one people assimilate with another. Zhang's (2016) study of chronologic and spatial orientation patterns describes dispersal routes that allows the reader to more easily digest such complex events. As we move from the Pleistocene to the Holocene, both Bellwood and Zhang concur that the subsequent development of domesticated crop and animal agriculture is crucial in the movement of humans into the earliest of prehistoric human settlements. This knowledge should take us another step closer to understanding humans and their peculiar walls. 


\section{BUILDING WALLS - FEAR MANAGEMENT AND OTHERING}

Historian Paul Trout (2011) theorizes that early Pleistocene hominins, under continual and perpetual threat from lethal predators, dealt with such visceral dread through both the development of rudimentary fear-management strategies and, ultimately, the construction of walls. The need to recognize, manage and assuage the constant anxiety of human meat-eating carnivores throughout the length of the Pleistocene epoch are likely amongst the selection drivers coordinating the successful survival and evolution of our hominin ancestors. According to Trout, at the foundation of such strategies must be the early urgency to anthropomorphize human environments, perhaps in an attempt to better understand the intentions of predators by translating human traits and desires upon them. In the struggle to respond to survival stressors imposed by predators, any edge in anticipating danger as a mechanism to better manage and respond to fear would give early humans some marginal evolutionary advantage. Prior to acquiring semantic language skills, early humans likely communicate fears, as well as mechanisms for fear regulation, to others in their small groups via mimetic story-telling. Connected to Trout's line of reasoning, neuroanthropologist Merlin Donald (1991) writes that mimesis is an intermediate step between episodic culture and semantic culture in which mimesis "... involves the invention of intentional representations" (Donald, 169). "When there is an audience to interpret the action, mimesis also serves the purpose of social communication" (Ibid.: 169). Mime is intentional communication and it leads to reciprocal behavior. "Toolmaking was probably the first instance of behavior that depended entirely upon the existence of self-cued mimetic skill” (Ibid.: 179). Mimetic culture, probably first evolving 
with Homo erectus, is the precursor to all modern human cultures eventually leading to mythic culture and, with Homo sapiens, to language-based semantic culture. Working together within this primitive "net of social obligations" (Trout, 236) is perhaps one of the earliest forms of human Othering, a reflection of "biases, potentialities and tendencies to react to threats" of various kinds (Ibid.: 259).

Othering can be both horizontally-, as noted in the examples above, and verticallyintegrated within any human culture. Jonathan Haidt (2012), the American social psychologist, claims that research on tribal cultures shows us the closeness in which human and non-human primates dominate others within their species through the formation of such vertically-integrated hierarchical group-structuring processes. Within the last million years, early humans undergo a unique "political transition" (Haidt, 198) that allow them to live a more egalitarian social life by formalizing hierarchical group-structuring processes. From this, “... it becomes easy to see how early humans developed the ability to unite in order to shame, ostracize or kill anyone whose behavior threatened... the rest of the group" (Ibid.: 199).

As xenophobic social beings, Homo sapiens "instinctively divide humanity into two parts, we and they (Harari 2015, 195). According to historian and philosopher Yuval Noah Harari, the ability to maintain material and subjective compartmentalization amongst humans is accomplished primarily through the imagination, construction and consistent reification of imaginary orders (entities that have essential value solely because members of any given communal grouping cooperatively believe they are of value) - kinship, religion, political orders, currencies and boundaries, for example. Such social cooperation is a trademark of our species and endures in our unique abilities to construct barriers, define 
limits and voluntarily allow the controlled flow of people, animals, goods and ideas across such boundaries. Social cooperation, partly based upon Othering expressed through the existence of imaginary orders, is the 'mythical glue' (Ibid.: 38) that binds the human species allowing for the earliest stages of societal cohesion and cultural formation.

Neuroscientist and author Sam Harris (2010) reflects upon the spectrum of human territoriality as it relates to wall-building as he writes, "evolution may have selected for territorial violence... to propagate [our] genes... but our collective well-being clearly depends upon our opposing such natural tendencies" (Harris, 101). As "human evil is a natural phenomenon, and some level of predatory violence is innate in us" (Ibid.: 100), human walls provide an opposing mechanism to conflict, while, at the same time, allowing for the establishment of border zones that facilitate a more slowly restrained transition within and amongst opposing factions.

While economist Henk van Houtum and and anthropologist Ton van Naerrsen (2002) primarily address issues of bordering and Othering in a contemporary and more highly-refined context, their essay has much to say about deeply-entrenched patterns of human migration, involving not just individuals but a reticulation of social humans, and the associated boundaries utilized to bring order and structure into a chaotic world. Like anthropologists Suzanne De Atley and Frank Findlow (1984), van Houtum stresses that borders are not fixed in time and space, rather borders "symbolize [changing] social practice[s] of spatial differentiation" (van Houtum, 126). Throughout the history of human migratory movement, borders have existed to create and regulate spatial place-making so as to "erase territorial ambiguity and ambivalent identities ...", as well as “... shape a unique and cohesive order" (Ibid). The authors also introduce the concept of border 
transition zones serving a vital role as “... spatial mediators of often latent power... and practices of places in society" (Ibid.: 128). Such peripheral border zones, through the reality of their inhabitance by Others, serve as "cultur[al] in-betweens" (Ibid.: 130) buffering the presumed dangers of alien people and their practices. The constellation of Othering is being constantly reformatted and reproduced as borders form and are transformed, so as to allow those responsible for building boundaries to maintain a "formatted order [in] a territorially demarcated society" (Ibid.: 134). In conclusion, the authors state that the security of territorial order is ultimately preferred over the unknown dangers of territorial disorder.

Haidt (2012) describes two unique human qualities (at least, vis-à-vis other primates) that contribute significantly to our tendencies to delineate boundaries and build walls. First, humans are territorial creatures whose offspring require significant resources for survival, development and evolutionary success, all the while under enormous pressure from neighboring groups undergoing similar pressures. Second, based upon evolutionary culturalist Peter Richerson and anthropologist Robert Boyd's (1998) “tribal instincts hypothesis" and the related concept of tribal ultra-sociability (or eusociability) human groups have always been, and remain, in conflict with neighboring groups. Any symbolic marker arising through cultural innovation, including boundaries of various types, that assists in tribal identification and intra-group cooperation gives an adopting group advantages against those not adopting such devices.

\section{Cultural And Cognitive Co-evolution}

Melding the conjecture surrounding early prehistoric human mobility with the realities of modern human wall-building is a significant leap, but academic literature exists 
that can assist us in discussing the salient connections. Cognitive psychologist Steven Pinker informs us that the idea of cognitive and cultural co-evolution, and the resultant human behavioral patterns, is critical in the ultimate prosperity of both early hominids and Homo species as they successfully master the majority of earth's ecological niches. Pinker (2010) offers fascinating insight into the why and how of our species' unique ability to perform socially complex tasks, such as the conception and erection of boundaries. The author proffers that modern humans, via a combination of natural selection and trial and error, simply evolved to fill their own cognitive niche. Homo sapiens finds itself cognitively atop the animal kingdom through its singular ability to combine technological know-how, cooperation among non-kin and grammatical language (that is, through reasoning, cooperation and the sharing of information) into favorable social feedback loop mechanisms that result in vast, complex arrays of social skill-sets and cultural advances. The author writes that " ... initial increments in cooperation, communication, or know-how altered the social environment, and hence the selection pressures for ancestral hominids" (Pinker, 3). Trevor Watkins (2004), a classical archaeologist, also refers to the feedback loop mechanisms seen in the process of cognitive and cultural co-evolution that allow "human minds [to] develop not just new ideas but new cultural media that in turn engender new ways for minds to think" (Watkins, 13). Such cultural progression has been gained through steady and incremental development that has been markedly facilitated by our grammatical language that "... not only lowers the cost of acquiring a complex skill but multiplies the benefit" (Pinker, 3).

Merlin Donald (1991) eloquently offers a working framework for the inviolable evolutionary connections between cognition and culture that lie at the foundation of the 
imagining, creation and maintenance of human-built walls. At the most basic level, increasing hominid cognitive function is a result of, as well as driven by, the process of encephalization (the growth in brain size), especially the relative enlargement of a portion known as the frontal cortex vis-à-vis other areas of the brain. The "unitary hypothesis [of cognitive development] states that a single adaptation (brain size) would suffice to trigger the novel cognitive capacities of humans" (Donald, 106). That is, as the hominid brain (really, just a neural computer) increases with size, the augmentation in available neural components and pathways allows for a multiplication of computational power. Harris (2010) agrees, writing that "... we can account for the ways in which culture defines us within the context of neuroscience..." (Harris, 2).

As the hominid line ascends, a gradual continuous process of encephalization is seen, though there are several stages of more abrupt, marked changes in cranial capacity most notably at $4 \mathrm{Ma}$ (apes to Australopithecines); $2 \mathrm{Ma}$ (Australopithecines to Homo erectus); and, 0.2 Ma (Homo erectus to Homo sapiens). So, between these relatively rapid and significant changes in brain capacity, there exist longer periods of subtle change. Accompanying cranial capacity enlargement, there are evident, accelerating rates of hominid cultural change, as well, and this is an important connection to recognize. Cognitive changes and cultural changes occur hand-in-hand, or co-evolve, and are especially fecund at the transition of Homo erectus to Homo sapiens as “... radical cultural change has tended to correlate with increases in brain size" (Donald, 100). Counter to this pattern, around $0.1 \mathrm{Ma}$ or so, cranial size ceases to increase, yet cultural innovation explodes. Primarily, it is the selection and evolution of an appropriate vocal anatomical tract, and that tract's endowment to produce speech, that results in this particular 
exponential amplification of intellectual power (without the usual accompaniment of growth in cranial capacity) in our species. With the advent of language now accompanying the neuro-cognitive plasticity of the human brain, semantic culture (the ability to integrate memory, associations and language) firmly takes root. While an ape's cultural system is episodic in nature and apes live moment-to-moment (or within the present) continuously reacting to short-term, concrete situations (thus, apes are deemed to be cognitively confined by situational limitation), humans utilize semantic memory which is deeply dependent upon the relationships of symbols, words and memory. Thus, we see that cognitive ability steadily co-evolves with cultural capacity. This co-evolution allows humans to steadily progress from episodic- to mimetic- to mythic- to semantic-based cultures. Furthermore, "the selection advantages accruing to a species capable of [such progressive] cultural invention would be tremendous" (Donald, 10).

In tracing the steps from and making the connections amongst a highly mobile species to one capable of constructing boundaries that impede mobility, Donald describes a four-level process of evolution. The genetic level is the basal level and, evolutionarily, it is relatively slow-moving. Next, there exist three subsidiary levels - developmental (also slow-moving), learned and sociocultural. The learned and sociocultural levels are fastmoving and speed up the overall evolutionary process. In this regard, "intelligence... becomes much more than the capacity and skill of one individual mind. Rather, it includes the entire knowledge-structure of the species" (Ibid.: 158). As variation is generated at all four levels, the variants are tested, and the successful variants are selected and then regenerated" (Ibid). In essence, Donald states that brain expansion is driven by social intelligence rather than instrumental intelligence (i.e. toolmaking). Ergo, increasing social 
group size is at the root of brain expansion and, therefore, intellectual abilities capable of maintaining enlarging group size likely lie at the foundation of cultural innovation. Further expanding this line of thought, competition is not a function of individual survival strategy so much as one of group survival strategy and “... would thus test particularly [a species'] ability to act as a cohesive society” (Ibid.: 209). Hence, “... cognitive innovation [may have] granted one group of hominids, as a group, a significant cultural advantage over another" (Ibid.: 210).

\section{TERRITORIAL COMPARTMENTALIZATION AND WALLS AS SOCIAL CONSTRUCTIONS}

Based upon the studies of material remains, anthropologists, such as the late $\mathrm{H}$. Martin Wobst (1974), are able to "generate inferences about general [Paleolithic] cultural processes... [in order to better understand the foundations] of post-Pleistocene and modern cultural systems" (Wobst, 148). In his analysis of boundary conditions for Paleolithic social systems, one of Wobst's assumptions is that Paleolithic social groups were territorial and "that members of a given social group moved within an area which was more or less delineated by social factors [and] by the proximity of other such groups..." (Ibid.: 151). Wobst goes on to describe the integration of social networks of loosely affiliated and variously sized minimum bands into a maximum band. It is through cooperative efforts within this maximum band unit that territorial limitations are defined and biological and cultural survival is most efficaciously proliferated. Elegantly aligning the evolution of the social, political and economic framework of societies, from bands to tribes to chiefdoms to states, Diamond (1997) infers that the transition from tribes to chiefdoms, around $7.5 \mathrm{ka}$ (alongside the accompanying political change from egalitarian societies to ones with more centralized authority, the economic change from hunter-gatherer to agricultural 
domestication, and the social change of increasing class stratification) requires numerous facilitating technologies. It is likely no coincidence that architectural advances - both structural and landscape-modifying - explode at the same time as a mechanism to allow for the separation of people no longer living in small, egalitarian groups, but rather in larger, vastly more complex ones.

In their analysis of frontiers in prehistory, De Atley and Findlow (1984) appreciate that human boundaries are fluid phenomena and that there are variations seen in the approaches to boundary building across a temporal spectrum. Investigating the peripheries of cultures, the authors describe that the merging of cultures "often do not coincide to form a single line of demarcation" (De Atley and Findlow, 1). While humans strive to draw clear lines of demarcation in their attempts to declare territorial objectives, "the difficulty lies in the expectation that human groups have margins like organisms do..." (Ibid.: 2).

Geographer Robert Sack (2016) defines territoriality as a “... spatial strategy [used] to affect, influence, or control resources and people ..." (Sack, 1) and as a “... primary geographical expression of social power" (Ibid.: 5). Sack highlights the perspective that while mobility is biologically motivated, territoriality is socially inspired. Further, Sack notes that territoriality can be expressed with either physical or non-material walls as long as three conditions are met: 1.] it must involve a form of classification by area; 2 .] the extent of the area must be communicated; and, 3.] any individual instance of territoriality “... must involve an attempt at enforcing control over access to the area and things within it, or to things outside of it by restraining those within" (Ibid.: 21-22). At the root of territoriality as a social construct, Sack states that hunter-gatherers are able to live amongst themselves in an egalitarian fashion, yet with the rise of civilizations - and the proliferating 
populations associated with them - there arises a societal need for territoriality in order to control and classify people within these enlarging groups. Sack notes that an evident example of such a need is the evolution of complex architecture - with multiplying walls and multi-storied structures necessary for the allocation of spatial resources and social classifications within an enlarging group.

Steven Kuhn (2009), the evolutionary social behaviorist, has studied the earliest of discovered modern human-modified walled structures that have been identified within Ucagizli Cave in Hayat, Turkey, near the Turkish and Syrian borders in the northernmost aspect of the northern Levant. First occupied as far back as 41,000 years BP, the cave contains an array of low-lying, large limestone blocks that were purposefully placed by its inhabitants. While the functions of these early Upper Paleolithic rudimentary walls are not fully clarified, the hypothesis is that they were utilized to delineate spatial frameworks for either food preparation, hearth and fire-making or bedding areas within the larger structure (Kuhn, 92). Discussing possible impetuses for the construction of such early human walls, as part and parcel of longer-term social changes and evolutionary cultural developments, social geographer Ian Kuijt (2000) raises profound and interesting queries into possible human responses to increasing demographic pressures (specifically, social crowding) in the communal villages of the Near Eastern early-Neolithic. In relatively rapid order following the wide-spread domestication of plants and animals in the south-central Levant, hunter-gatherer societies began the gradual transition toward increasing sedentism in aggregated communities. Such aggregation eventually led to population growth and, subsequently, increasing local population pressures. Kuijt argues that such pressures logically result in, and are pivotal to, cultural changes driven by both subsistence and social 
concerns (Kuijt, 78). In addition to the hardships that develop within an expanding population in accessing limited food resources, the author notes that "under conditions of population aggregation, animals and humans respond negatively to a number of features in their environment: congestion, loss of control, loss of privacy, and information load" (Ibid.). These real and perceived pressure drivers are ultimately expressed, at least in part, in modifications to a community's built environment. Therefore, "in order to ensure privacy, or the ability of individuals to retain control over access to other people or resources, or, more likely, restrict access, people may construct physical boundaries to impede movement and access, as well as to develop social barriers to interpersonal interaction" (Ibid.: 79). Resulting innovations include the compartmentalization of buildings and property, as well as the further development of architecture in the form of houses divided by walls and multi-story buildings, in order to deal with such dynamic and entangled economic, environmental and social concerns. [Anthropologist Marion Cutting (2006) utilizes the term 'space syntax' (Cutting, 232) to cohere the analysis of architecture, built landscape and spatial access as these topics relate to social meaning and cultural change.]

In part, the burst of architecture in the early stages of the Holocene denotes the growing significance of humans utilizing their built environment as a forceful mode of external symbolism. Trevor Watkins (2004) endorses the hypothesis that the human ability to externally express symbolism through the built environment rests squarely upon a foundation of an antecedent "co-evolution of human cognitive faculties and culture" (Watkins, 5). Clearly, the connections between increasing sedentism, growing demographic pressures in the face of multiplying populations and various sorts of built 
environments is not coincidental. As sedentary peoples respond to changing demographic pressures, their placement of increasing emphasis on boundaries and architecture is a resultant "materialization of structure"... that "[introduces] spatial organization and allocation as an ordering visual dimension" (Ibid.: 11).

The literature is replete with myriad examples of why humans built walls in their past. In his edited volume, historian James Tracy (2000) advances the interpretation of human wall-building through the analysis of cities and their walls - urban enceintes - over a nearly 10,000- year period. Referencing Jericho's earliest walls from $8000 \mathrm{BCE}$ and extending through $18^{\text {th }}$ century European colonial fortifications, the author asks questions about the circumstances surrounding urban wall-building endeavors, including the pragmatic needs for, as well as the symbolic cultural and political meanings of, such walls. In addition to Tracy's work, archaeologist Graham Connah (2000) writes on 'contained communities' in tropical Africa dating from around the $10^{\text {th }}$ century BCE. Contained communities are called such as they comprise a group of people who find common reason to separate themselves from other groups by placing themselves in a container, generally some communal unit bounded by stone, mud, natural vegetation or natural water features. These low-walled structures often protect homesteads and livestock from "wild animals and marauding neighbors" (Connah, 23). Later African structures, like those found in Bigo, Uganda dating from the $15^{\text {th }}$ century, function as earthwork enclosures for penning cattle and giving prestige to those living in the community. Extensive, more complex earthworks consisting of combinations of banks and ditches, in and around Benin City in southern Nigeria, surround individual settlements and their agricultural lands as a "... means of laying claim to the resource base necessary for a settlement's continuance and well-being" 
(Ibid.: 35). Connah posits that the unusually extensive and staged nature of these particular earthworks suggests an adaptive process undertaken in response to increasing population pressures. In her essay, historian Kathryn Reyerson (2000) writes that medieval Europe, especially the period spanning the $12^{\text {th }}$ through $14^{\text {th }}$ centuries, is a period of significant wall-building, primarily in response to the Hundred Years' War. Such urban walls, in her view, “... had a symbolic significance as emblems of urban identity as well as a pragmatic, defensive purpose" (Reyerson, 88).

In this same volume, historian Richard Kagan (2000) considers a Spanish culture that placed value on physical, as well as non-material boundaries (the 'spiritual walls' of colonial Spanish America) dependent upon specific cultural context and intent. "Throughout fifteenth- and sixteenth-century Europe [material] walls constituted a town's badge of honor, a sign of grandeur, wealth, and importance" (Kagan, 117). Such walls also played a vital economic function, facilitating the taxation of goods as these goods were shifted into towns. City walls also served as an "urban prophylactic" as they "were closed whenever plague or other diseases posed a threat". Perhaps most significantly, "walls constituted a symbolic boundary, delineating the area within which justice... ruled supreme" (Ibid.). As Spain's expanding imperial power spreads into colonial Spanish America in the $16^{\text {th }}$ century, historians observe a relative paucity of physical walls (at least in contrast to the Old World) as administrators prefer the absence of durable material walls in the protection of their towns. In their feverish push to emphasize religion and piety over warfare, town administrators in the New World rely heavily on 'spiritual walls'. The concept of spiritual walls as a form of protecting one's citizenry is an extension of Spain's religious conservatism and reliance on the literal words from the Old Testament "thou shalt 
call thy walls salvation and thy gates praise” (Ibid.: 128). As such, “... it was religion, not walls, that offered the city its best protection" (Ibid.) against both external and internal discontent. While this is a calculated risk, city officials make the decision to invest any available labor and tax revenue not on the construction of physical walls, but rather on the critical resource and infrastructural needs of sustaining its population and extracting mineral wealth for the motherland. Maturing Eurocentric concepts of policía (Spanish) and polis (Greek), or polity, are clarified and reified both on the continent and in its colonies during this time as walls, whether material or non-material in form, constituted one's broader communal cultural identity and accompanying benefits in the form of a blended “... law, order, morality (Ibid.: 134)... justice, religion and [economy]” (Ibid.: 131).

David Newman (2003), the political geographer, describes the practice of bordering as one "through which territories and people are respectively included or excluded within a hierarchical network of groups, affiliations and identities" (Newman, 13). The author succinctly describes the numerous typologies of borders. These borders span from hard, concrete and rigidly geographical boundaries to ideological boundaries that are more pliable and less spatially fixed. All borders contain some inherent degree of permeability. The permeability of trans-boundary movement applies not only to humans and their goods, but to information and ideas, as well, and results in the formation of hybrid trans-boundary zones that reflect a mixing and fusion of people and their cultural affiliations as one moves across the zone in either direction. Therefore, borders serve to "offer protection against infiltration of values which are not compatible with the hegemonic practices of the majority .." (Ibid.: 14). Both territorial and cultural compartmentalization, through the process of bordering, allow for the "formal [and orderly] construction of difference" (Ibid.) so vital to 
the reality of defining and acknowledging self and Others. With this in mind, all borders, regardless of taxonomy, are social institutions that are continually imagined and maintained as they are ceaselessly "delimited and demarcated" (Ibid.: 17) by humans. In his essay, Newman expertly balances the idea that, in the broadest view, bordering processes function to both simultaneously impede movement and to create points of interface.

In her work, anthropologist Setha Low (2009) introduces the important, though often misunderstood, concepts of space and place. Essentially, space is a geographical term that describes an area that can be demarcated by geographical markers or coordinates and that, in and of itself, has little other meaning. On the other hand, place is cultured space that is, places "are socially constructed by the people who live in them... they are politicized, culturally relative, and historically specific ..." (Low, 22). Describing borders in biological terms, Low places in them the function of providing the "social skin" (Ibid.: 27 - rather, the common last frontier - for the human group organism. And, it is this boundary organ that serves to protect us from harm, as well as to allow areas of interface and connection with the outside world. In this manner, transitional zones expedite the transformation of bounded space into integrated place. Illustrating a similar perspective, Tuomas Forsberg (2003), the political scientist, stresses the importance of the social constructivist view of territories and their borders. That is, borders have meanings, beyond their physical existence, because of how people "think of" territories and their boundaries. (Forsberg, 10). Hence, “in different cultures borders can be 'barriers', 'filters', 'meeting points' or 'crossing points' ... therefore one should ask how the spatial concepts are socially produced and what those symbolizations imply and cause" (Ibid.: 11). 
Anthropologist Tim Ingold (2005), in his discussion of landscape archaeologist Christopher Tilley's work, interprets Tilley's writing as explaining that material objects in the physical world (including borders of various sorts) are "stand in[s]" (Ingold, 123) for cultural concepts. That is, these objects are simply "metaphorical resources for the expression of social... principles" (Ibid.) and that the interpretation of the meanings of objects in the physical world is entirely contextual and temporal. These objects are given meaning by the people interpreting their presence at any given time under a variety of possible circumstances, making "all human experience... fundamentally place-bound" (Ibid.: 125). [George Friedman (2010), the geopolitical strategist, devalues the particular significance of such a variety of possible circumstances. In his book on the geopolitics of the modern world, Friedman argues that human behavior, over the long-term, is essentially repetitive in nature. Given a wide variety of informational input, humans will eventually make similar decisions because "geopolitics is about memory" (Friedman, xviii). Perhaps this helps explain the consistency of human wall-building despite varying context and temporalities.]

Political geographer Reece Jones (2016) comments on several issues of relevance in regard to this literature review. The author refers to the United Nations Convention on Refugees definition of refugee to highlight the persecution of those who fall out of the boundaries of a particular race, religion or nationality, or political or social grouping. Jones notes that in such instances fear is essentially bilateral - citizens fearing Others and aliens fearing persecution by a sovereign state (Jones, 20). While the author notes that the building and maintenance of borders is all too often ineffective and lacking "meaningful impact" (Ibid.: 36), at the same time, he acknowledges that barriers can serve as compelling 
offensive and defensive strategies. Jones writes that ancient walls are erected in order "... to [establish territoriality and] prevent undesired movement into and out of [ruler and/or state] area[s] of control" (Ibid.: 92) and, thus, have overt economic and military functions. Furthermore, walls have important symbolic roles in representing the power of the state. Borders, Jones declares, “... are artificial lines drawn on maps to exclude other[s] from access to resources and the right to move" (Ibid.: 112). As a rather striking contrast to more visually-evident physical barriers, Jones examines the Law of the Sea (LOS) ratified in the late $20^{\text {th }}$ century. The LOS, with well over a hundred national signatories, "encloses all of the oceans and transforms the open ocean into administered space ..." (Ibid.: 115). By surveying the ocean and allocating its resources to the national interests that mutually agree with lines demarcated only on a map, the LOS highlights that barriers can indeed exist without the need for brick and mortar.

\section{THE EXPRESSION OF POWER, THE DOCILE BODY AND SPATIAL PRACTICES}

Modern states have developed multiple non-material barricades in their armory of control that are useful for the purpose of wielding biosocial power over marginalized and disenfranchised segments of their populations. Human geographer Nicholas de Genova and Nathalie Peutz (2010), an anthropologist with a focus on Arabic studies, are concerned with issues of mobility, especially in regard to the perplexing concern of deportation which they define as "the compulsory removal of 'aliens' who have allegedly violated... material and symbolic boundaries... from the physical, juridical, and social space of the state" (De Genova and Peutz, 1-2). The authors visualize deportation as a global response to a social order that increasingly lacks control resulting in growing, broad insecurity. Global governments utilize deportation to regulate freedom of movement in response to this 
insecurity as a mechanism that fortifies national control over space and territory and, thus, reifies "... political, racial and class-based boundaries" (Ibid.: 4). Thus, the modern sovereign nation-state is divided between “... 'rightful' members (citizens) and relatively rightless nonmembers (aliens)" (Ibid.: 7).

Sociologist Saskia Sassen (2014) focuses on the concept of the systemic edge [or, "space of expulsions" (Sassen, 221)] the place beyond which humans are expelled from economic, social and biospheric processes (Ibid.: 211). Different than a geographic border in our increasingly global world, this edge serves as a forceful, incorporeal barrier delineating the social niche that those of lower economic means will occupy. Living beyond this edge disallows individuals to access resources and assets once assumed to be an inviolable part of their communal contract. Javier Auyero (2012) discusses a similar idea, that of the state exercising the power of making people wait as a tool of subjugation. Auyero, a Latin American sociologist, notes that "waiting is stratified,... socially patterned and responsive to power differentials" (Auyero, 27). As marginalized populations attempt to garner access to limited state social resources, the state exerts power. The state accomplishes such control through forcing the marginalized to wait for services proffered by a sluggish, unaccountable and faceless state bureaucracy. Thus, these people are transformed into dependent, subordinated subjects, or "patients of the state" (Auyero). Aligning her insights with Auyero, Julie Peteet (2017), an anthropologist whose body of work spotlights resistance and culture in the Middle East, clarifies the existence of similar power dynamics between the occupier Israel and its Palestinian subjects. Peteet notes that the intentional ambiguity of "tempo, speed, and direction..." (Peteet, 96) on roadways and, especially, while waiting at checkpoints "[reifies] relationships of dominance and 
subjugation" (Ibid.: 98). Yet, as to the waiting for documents, checkpoints and, even, the right of return, "this is not ordinary waiting, this is state-enforced waiting as a form of punishment and control" (Ibid.: 143). Among other things, what results are areas of urban displacement, or, when referring to Buenos Aires, what Auyero describes as “neighborhoods of relegation" (Auyero, 41). Availing itself to making its occupied subjects wait, Israel not only denies Palestinians the agency necessary to be meaningful actors, but also creates relegated Palestinian spaces in homes, villages, agricultural lands and settlement camps. As such, Palestinians become further entrenched in their role as "pawns in the midst of the state's not-quite-evident forces" (Peteet, 153).

An interesting, more distant historical analysis of this issue can be found in Theresa Singleton's (2001) investigation of the spatial organization techniques appropriated by late- $18^{\text {th }}$-to-early- $19^{\text {th }}$ century Cuban coffee plantation slaveholders to control their slave populations. Described as being part of an interrelated three-part dialectic relationship (with the slaveholder's control in continual conversation with a slave's resistance) slaveholders employed physical, emotional and cultural means to control the spatial arrangements of slaves. The primary mechanism of containment was a combination of barracones (housing units divided into cells) surrounded by high walls. Such devices “... served as a material manifestation for recognizing the intention of slave flight" (Singleton, 104). As Singleton, an anthropologist specializing in African-American archaeology, notes, one forceful mode of emotional control of the enslaved population was surveillance via a panoptic mechanism accomplished by the placement of bell towers or slave holder quarters at high points within the plantation resulting in perpetual surveillance of the slaves. 
Modifications of the built-environment continued to evolve as significant weapons in controlling this New World labor force.

Tim Creswell (2001), knowing that mobility, space and power are at the core of modernity, opens with a vignette recounting Edwards vs California, a mid-20 ${ }^{\text {th }}$ century U.S. Supreme Court case spotlighting the issue of an individual's right to interstate mobility. The case highlighted the Court's belief that “... human movement is made meaningful in social and cultural context" (Creswell, 12), as well as in a political context, and that, according to Supreme Court Justice William Douglas, "placing an impediment on personal mobility... [dilutes]... the rights of national citizenship and [impairs]... the principles of equality" (Ibid.). Assuming that such a right to mobility exists in most world democracies, the strong-armed limitations on such movement (and, the nullification of mobility as an inherent human right) seems both purposeful and conspicuously egregious. Yet, as Creswell, a human geographer, discusses, the reining in of mobility is about much more than inhibiting movement from Point A to Point B. In essence, it is about the raw display of biological power as a stratified society attempts to more clearly define social divisions between the occupier and the occupied, or the citizen and the savage. By utilizing barriers that impede mobility, states control not just spatial but also temporal relationships between those on either side of a boundary "... imbued with an interrelated set of powerrelations and meanings" (Ibid.: 24). Rather than broadly imparting a population with the right of mobility generally recognized as innate to humans, that right is allocated in a zerosum game fashion, as if the powerful may remain progressively mobile only to the extent that the subjugated become diminishingly so. 
Discussing these same dynamics, geographer Reece Jones (2016) notes that "placing uniformed military troops on [a] border has a powerful symbolic and normative effect. It also contributes to media narratives that describe the border as a war zone" (Jones, 42). As an example, Israel continues to effectively brand itself as antithetical to the nomadic, terroristic Palestinian Arab, and, therefore, maintains a border and military presence around and about the West Bank as a clear demarcation between a civilized, Eurocentric Israel and the wilderness of an untamed, pre-Enlightenment Palestine. Such regional interpretation of the global border regime is “... now seen as a key function of the state" (Ibid.: 48). As a central objective of the United Nations, the recognition and maintenance of its member nations' sovereign borders disadvantages Palestine. While its immediate neighbors (Egypt, Syria, Jordan and Lebanon) have the relative security of international recognition of their borders by the UN, "Palestine has not yet become a full UN member, so its territory is not formally established..." (Ibid.: 54). Ergo, conservative Zionist factions within Israel are able to continue to mold policy within Israel in order to claim additional Palestinian lands that fall within the claims of "biblical Israel", essentially “... all of contemporary Israel and Palestine” (Ibid.: 54). The potent triad of UN support of the global border regime, the West Bank Wall and Israel's military might, in addition to the ingenious Israeli marketing of the mythical-historical narrative of claims to the entirety of Palestine, is a compelling force in the maintenance of a status quo that allows for the existence of a Palestinian homeland continually diminished in strength and size through the pragmatic realities and symbolism of a walled structure.

Sociologist John Torpey (1998) argues that “... modern states, and the international state system of which they are a part, have expropriated from individuals... the legitimate 
means of movement, particularly, though by no means exclusively, across international borders" (Torpey, 239). States do so primarily through a mechanism of controlling the modes of identification of its citizen and non-citizen populations as these populations “... become dependent on states for the possession of an 'identity'... which may significantly shape their access to various spaces" (Ibid.). Furthermore, "in this regard, people have to some extent become prisoners of their identities" (Ibid.: 256). As this relates to the typical Palestinian, the Israeli government is able to effectuate such identity control through the use of registration and identity cards, along with accumulating biometric data on its Israeli and Palestinian populations, allowing the Jewish state to "... 'embrace' their members more effectively and to exclude unwanted intruders" (Ibid.: 241). Such monopolization of movement has been integral to the formation of the modern state from its more ancient components of a “... panoply of empires and smaller city-states and principalities" (Ibid.: 242). Certainly, Palestine is no exception, as such territorial drift is mirrored there as multiple Palestinian 'empires' are engulfed by an ever-growing Jewish nation. From a Zionist perspective, Palestinians are simply being asked to “... tender unto Caesar what is Caesar's" (Ibid.: 244).

\section{The Production of Mobilities - Mobility, Space And Power}

Anne Jensen (2011) gets to the crux of mobility, space, boundaries and power as she "... investigates how the making of mobility intertwines with the spatialities and is played out under the workings of multiple forms of power" (Jensen, 256), and as she describes “... mobility [as] an ingredient in a basic social and political logic...” (Ibid.: 262). The author, a social scientist, likens mobility to a form of social capital, thereby the lack of which serves as a fundamental basis for social inequality. An “... unequal 
distribution of mobility... [leads to the diminishment of] subsequent opportunities for going to work, upholding family ties [and] using leisure activities" (Ibid.: 257). Through the structure and symbolism of barriers and its effect on the slowing of time and shrinking of space, the powerful strategically manipulate the mobility of the subjugated in order to exhibit biopolitical power, further diminishing one's place in a region's complicated, stratified societal matrix.

Romola Sanyal (2014), an urban geographer, further clarifies the interplay of mobility and barriers as she writes of displacement and informal urbanism within Palestinian and Bengali refugee camps in Lebanon and India, respectively. The author describes common threads amongst these differing groups as they strive to express belonging and citizenship as part of the broader dynamic of declaring contemporary (or, the reclaiming of aboriginal) national citizenship. Aware of the perspective that founding refugees have to contribute to the story of a thesis as innately subjective as group-identity, Sanyal's juxtaposition of two disparate, post-colonial refugee camps allows her to make sweeping generalizations about the basic human need to reestablish identity in the face of displacement from one's ancestral home. The staking of place with the creation of settlement camps is both objective, with the establishment of physical borders, but also subjective in that it serves as a mechanism and venue for the recovery of lost voice and agency. In parallel conversations with Sanyal, Peteet (2005) notes that "refugee and migrant studies... raise issue[s] of displacement, cultural bricolage, and identities shaped by multiple geosocial sites." Furthermore, "migration theory [now accounts] for simultaneous engagement and disengagement with multiple places" (Peteet, 25). 


\section{HADRIAN'S WALL}

Adrian Goldsworthy (2018), an ancient Roman historian, presents a concise, wellwritten and multi-dimensional analysis of Hadrian's Wall, Roman Britain's most significant military fortification and imperial symbol. While focusing on the issues relating to the Empire's perceived needs for the existence of such a structure, as well as the 80 Roman-mile long stone and earthen rampart's $2^{\text {nd }}$ century planning, construction, staffing and, ultimately, early $5^{\text {th }}$ century abandonment, Goldsworthy also deftly places Hadrian's Wall in the context of broader, far-reaching Roman frontier policies. Convinced that "we should never think of [Hadrian's Wall] as intended for static defence" (Goldsworthy, 116), Goldsworthy determines that though the structure's curtain wall and its associated milecastles, turrets and forts served as a base for a highly mobile Roman field force, Hadrian's Wall had many other functions: as a stark visual representation of Roman strength, as an endpoint announcing the cessation of earlier Roman expansionary policies, as a border limiting the ability of barbarian tribes from the northern provincial frontier to raid imperial lands, as a way station controlling the movement of humans, animals and goods (along with the associated collection of tolls and taxes) across Roman territorial borders, and as a logistical and economic juggernaut having the capacity to keep tens of thousands of legionary and auxiliary troops engaged on behalf of the Empire. In this way, Goldsworthy's Hadrian's Wall serves as a fine overview of the important strategic issues surrounding the Roman Empire's decision to construct, maintain and utilize this structure throughout its more than three-hundred year annexation of provincial Britannia.

The FutureLearn course on Hadrian's Wall, created and moderated by classical archaeologist Ian Haynes (2014) and produced through Newcastle University's on-line 
education program, offers a comprehensive introduction to the ideation, construction, inhabitance and eventual abandonment of the Wall, as well as the society, politics and economy of ancient Roman Britannia in the early part of the first millennium CE. Individual sections of this video course include such insights as the geography of the Roman Empire, the far-flung origins of the populations serving the Wall and their place within the Empire's social class system, the structure of the Roman military that built and serviced the Wall, and insights into the cultural lives of the people occupying the frontier zone.

The echoes of distant human wall-building endeavors can be revisited and interpreted in myriad ways. Contemplating Britannia's ancient Roman road system, Nicholas Howe (2005) understands such a structure as “... [announcing] the relation between the colonizing and the colonized societies in a literally material form" (Howe, 29). The author, a scholar of Old English literature, also acknowledges the objective and symbolic importance of boundaries in delineating human endeavors and the contextual typology of bounded space - whether it be economic, political, topographical or cultural in nature. Specifically, in the case of Hadrian's Wall, this structure "had the effect... of marking the spread and maintenance of imperial power and civilization" (Ibid.: 33). Landscape archaeologist Richard Muir (2000) notes that boundaries became an increasing presence upon the landscape as human resource pressures resulting from increasing populations multiplied, with such boundaries "[serving] both instructive and symbolic roles" (Muir, 69). Boundaries allowed humans to organize their lives "within superimposed networks of overlapping authorities - authorities that controlled their beliefs, obligations and loyalties" (Ibid.: 75-76). Muir further notes that "the castle, the Roman fortress and the 
hillfort are seen, in their different ways, as power centres radiating influence and control across surrounding territories, responding to conditions in the setting and stimulating change" (Ibid.: 223).

With his essay in Archaeology, journalist Jarrett Lobell (2017) enlightens the reader on Hadrian's Wall, as well as on its creator and namesake. Hadrian, as ruler of a vast empire stretching from Britannia to Iraq in the east and the Sahara Desert to the south, reigned for twenty mostly peaceful years. Able to allocate resources away from the continued expansion of the empire under previous rulers and the associated costs of maintaining an engaged military force, Hadrian, instead, focused on expressing the power of Rome, both in the provinces and closer to home, through a formal program of architectural and artistic projects. Hadrian's construction of his eponymous Wall was part of this overall approach to the visual expression of power. But, lacking a natural geographic barrier to impede Celtic tribes to the north, this barrier also had a pragmatic, defensive purpose. Therefore, Lobell instructs us that Hadrian erected this wall to accomplish multiple objectives, both figurative and literal.

Roman archaeologist Robert Witcher (2011) considers the political uses of Hadrian's Wall "through an analysis of its [three] materialities" (Witcher, 4) - its archaeological remains, the texts, images and artefacts acknowledging the Wall, and "the landscape within which the Wall is situated" (Ibid.). According to the authors, while the contemporary interpretation of Hadrian's Wall focuses on its defensive application, a more complete historical understanding of the structure can only be realized through an extended inquiry into how these materialities are interpreted in an historical context. In this regard, the "... meanings of the Wall [are] mutable" (Ibid.: 6) as "perception is interpretation; 
[and,] senses and emotions are culturally defined" (Ibid.: 17). Anecdotally, modern businesses in the northern parts of Britain frequently use the 'Hadrian' brand to suggest that they are local and indigenous and, thereby, "enduring, solid and reliable" (Ibid.: 14). Such commodification of the Wall enhances contemporary interpretations of the Wall's uses, as well as facilitates false narratives of peoples living near the Wall into groups of either citizens or savages. In fact, the Wall drew people from many cultures to build, maintain and live within its shadows and, therefore, was a place of inclusion and assimilation. In this way, the Wall exemplified the multi-cultural milieu of being a citizen of the Roman Empire.

In their essay, Claire Nesbitt and Divya Tolia-Kelly (2009), who specialize in archaeology and heritage studies, respectively, take a comparable approach to Witcher in their attempt to more clearly decipher the socio-political or body-centered experiences of those encountering Hadrian's Wall - interactions the authors describe as 'embodied accounts" - so as to better understand "... the lives that have been lived in these places" (Nesbitt and Tolia-Kelly, 375). There are as many interpretations to the Wall as there are people who have experienced it. Thus, the Wall's embodied interpretations are not static, rather these interpretations are dynamic, fluid, and ever so personal as “ . .. history and local memories, which are made, re-made, and reflected upon at each encounter" (Ibid.: 377). Did the Wall - does any barrier? - serve primarily as a visual symbol of power? As a safety zone allowing the cautious separation from the feared Other? As a unique archaeologic relic to the inquiring antiquarian? As a convenient source of stone for local builders? Or, is the quintessence of any wall a combination of these and/or other elements? As the authors note, "the Wall has been a prism or canvas for viewing the political ideas 
and identities in [temporally separate] periods of time" (Ibid.: 384). Embodied histories of the Wall assist to "enliven linear histories" (Ibid.: 385) thereby creating multifaceted accounts of materials and ideas often visualized through a compressed lens.

David Breeze (2006) and Brian Dobson (Breeze and Dobson 2000), both archaeologists and Hadrian's Wall scholars, are responsible for authoring two of the most detailed descriptions of the storied history of the structure. These works do an especially fine job of not only illustrating the Wall as a massive logistical and financial undertaking during the period of construction and occupation, but also of clarifying the breadth of the Empire's problem-solving during its presence in Britannia throughout Rome's early-tomid $1^{\text {st }}$ millennium occupation of the island. Breeze's latest edition of Bruce's Handbook to the Roman Wall gives a detailed assessment of the archaeology of the entire length of Wall allowing a meticulous reconstruction and interpretation of the material remains into an orderly and coherent story of this singular architectural structure.

Brent Sterling (2009) is primarily interested in deciphering a strategic analysis (from the perspective of Roman imperial governance) of Hadrian's Wall, as opposed to the more operational concerns of its logistics and maintenance. It is in that vein that security studies specialist Sterling writes of the Wall as the prime example of Emperor Hadrian's "ambitious goal of establishing an anti-expansionist orientation for Rome that would outlast his reign" (Sterling, 76). Furthermore, Sterling delves into the decision-making processes that underlie the building of strategic defense systems in general. As one example, Hadrian's Wall, like other ancient and contemporary barriers, plays a crucial role in imperial strategic deterrence by highlighting an enemy's "consequences for aggression (deterrence by retaliation) ..." as well as "their low likelihood of achieving their objective 
(deterrence by denial)" (Ibid.: 78). The author surmises that territorial security is normally achieved through the satisfactory blending of a combination of strategic, military, diplomatic and psychological objectives specific to the needs of the party seeking an improved sense of security. In his chapter on Hadrian's Wall, Sterling stresses the importance of such an imposing structure on the central role of psychological dominance in attaining a higher level of security vis-à-vis Rome's enemies.

\section{THE IRON CURTAIN}

An analysis of the drawing of the Iron Curtain post-World War II, Anne Applebaum's (2013) work details the multiple tools implemented by the Soviet Union in its creation of this dense, ideological border between a totalitarian Eastern Europe and the democracies of Western Europe and the United States. This book has a particular focus on events in Poland, Hungary and Germany, though parallels are drawn and referenced for the other Soviet bloc countries, as well. According to Applebaum, a Pulitzer Prize winning author and historian, the key to the development of a mechanism to restrain the flow of information, both intra-bloc and inter-bloc, was the establishment of a Moscow-controlled secret police force in each of the countries under the auspices of the Red Army. The Soviet Union used a variety of violent techniques, including torture, incarceration in its infamous gulag system and execution as it attempted to inculcate populations in its socialist orthodoxy. Less obvious, yet just as effective, mechanisms of instilling and regulating the movement of ideas included the direct Soviet manipulation of political processes, youth organizations, religious entities, economic policies and the media (both newspaper and radio) in "[helping to] lay the psychological groundwork for the imposition of a new regime" (Applebaum, 33) on the path toward "the creation of a 'new' breed of communist 
man - Homo sovieticus" (Ibid.: 153). Applebaum's book highlights the efficacy of one ideological border's ability to inhibit the flow of information across it in either direction. Such ideological opacification disallows those behind the curtain from knowing what exists beyond it, as well as those beyond the curtain understanding what occurs behind it. Thus, the Iron Curtain, not made of iron but nearly as impenetrable as though it were, reminds us of the potential robustness of ideological barriers.

Villages separated by Germany's Iron Curtain, Sonneberg on the eastern side of the divide and Neustadt to its west, had been neighbors for nearly a thousand years. Their partition by the Cold War's daunting ideological barrier, or "wall in the head" (Sheffer, 4), one which both pre-dated and outlasted any physical manifestation of the physical barrier, is the focus of the work by historian Edith Sheffer (2011). The mundane, ordinary behaviors, beliefs and daily actions of Germans on either side of the open spaces, permeable fencing and border gates that divide them come to reify their newly maturing identities as Soviet-style communists and democratic capitalists, respectively. Located along an old medieval trade route, the Burned Bridge crossing that separates these towns, essentially an unfenced, "invisible 'green border"” (Ibid.: 34) from 1945-52, serves not only as a marker of opposing cultures, but also thrives as a transformational space allowing hybrid economies and political philosophies to merge and reshape themselves during the early years of the Cold War. Such a border zone illustrates the power of non-material bordering processes to fuse existing cultures into unique border cultures, as well as the power of culture to reshape borders. Ironically, it is the porous nature of the early postWorld War II border at Burned Bridge that leads to the barrier hardening over the next several decades, as the "recast[ing of] communal life" (Ibid.: 45) into starkly contrasting 
cultures on either side of the boundary "transformed [this] tenuous [social, legal, economic and political] demarcation line into an entrenched [or, more structured and ordered] barrier" (Ibid.: 49).

In his discussion of the former Iron Curtain, Mathijs Pelkmans (2012) also highlights this ideological barrier's role in establishing dichotomous imagery - for example, "socialist protectionism versus capitalist laissez-faire; and, Soviet repression versus the freedom of democracy" (Pelkmans, 269). But, perhaps most evidently, Pelkmans, a specialist on the anthropology of borders, affirms the role of such boundaries (above and beyond any function they have in curbing the influx or egress of people and material goods) in impeding the flow of human culture as a mechanism to "... create order out of chaos" (Ibid.: 270). As the lines drawn establishing the Iron Curtain are often arbitrary, people sharing long-standing political, economic and social regional allegiances become separated and disconnected. In their attempts to lessen the resultant chaos, certain social dynamics, according to Pelkmans, develop once the boundary is secured. This new border becomes "their border" (Ibid.: 272) and idiosyncratic cultures establish themselves on just either side of the new divide in order to stabilize this unfamiliar space. Post-Cold War, as these boundaries begin to unravel and old alliances are renewed, Pelkmans describes wide-spread discomfort amongst the affected populations, many of whom wish to return to the ordered familiarity of the decades-long Cold War veneers. The author portrays such divides as having both "imaginary and physical permeability" (Ibid.: 274) and, in this way, illustrates the complexities of such imagined transition zones as "... no boundary line perfectly follows already existing patterns of differentiation" (Ibid.: 278). 
Anssi Paasi's (1998) thesis also focuses on the idea of "closed ideological border[s]" that are "ultimately reproduced in local everyday life" (Paasi, 670). Discussing the lengthy Finnish-Russian border solidified post-World War II, the author notes that such boundaries are not "static lines", rather they are "sets of practices and discourses which 'spread' into the whole of society and are not restricted to the border areas" (Ibid). Furthermore, geographer Passi notes that the creation of boundaries is frequently not a function of border areas per se. Instead, boundaries are frequently produced in governing centers, only to be functionally expressed and reinterpreted by those participating in the economic, political and social practices of the border areas. From a central governance perspective, the symbolism of modern ideological borders, such as the Iron Curtain, in regulating the boundaries of identity and culture is in checking the ebb and flow of ideas from one place to another, thus serving a vital role in nationalizing state peripheries (Ibid.: 671). Furthermore, Paasi stresses the view that borders are "social institutions and symbols" that are "historically contingent" (Ibid.: 679) upon the people and spatial relations in which they are expressed.

According to historian and author David Ryan (2016), the lasting implications of the Iron Curtain exist, in part, in their powerful ability to etch and reify collective memories - especially as its imagery is “... referenced frequently as shorthand for a bipolar configuration of power" (Ryan, 401). Ryan's notion of 'collective memory' refers to the interpretations of retained images, like the Iron Curtain, into the consciousness of a contemporary culture, especially as that culture then utilizes the imagery for "... [the] cultural process of... [continued] othering" (Ibid.: 402). Such semiotic barriers assist humans in structuring and interpreting the world “... in certain attractive frames and 
adherent ways" (Ibid.: 403). [Historian and archivist Arlette Farge (2013) employs the term mentalités "... which focus on daily life and the world of senses" as a way of explicating the contextual “... struggles and relationships of power" (Farge, 43) with contemporaneous interpretations of the archived past.]

At the conclusion of World War II, the Iron Curtain advantageously served both the West and the Soviet Union in the delineation of good versus evil with " ... all the evil, of course, being attributed to the opponent" (Ryan, 404). The Berlin Wall ultimately becomes "the [physical] manifestation of the metaphor" (Ibid.: 402) of the Iron Curtain. But, it is the ideological nature of the Iron Curtain that provides the underpinning of the Cold War cultural chasm that continues to exist between the East and the West. The imagery of the Iron Curtain, according to Ryan, facilitates the visualization of the dichotomies that exist between a totalitarian East and democratic West, thereby allowing for the compartmentalization of the binary ideologies and conflict that exist on either side of this imaginary geopolitical boundary. In this way, "the Iron Curtain... grafted an emerging framework to a cultural geography of Cold War Europe" (Ibid.: 408).

Delivered at Westminster College in Fulton, Missouri in the early spring of 1946, Winston Churchill's (1948) Iron Curtain Speech, through its emphasis on the symbolism imbued by this ideological boundary, is considered by many historians as the marking point of the initiation of the Cold War. Churchill wastes little time as he begins by framing the end of World War II as the victory of "civilized society, humble folk", through "the fraternal association of the English-speaking peoples" (Churchill, 7), over the vanquishing of "wicked men" in the struggle against "... the two giant marauders, war and tyranny" (Ibid.: 4). The fraternal association aligned against the tyrannical Other, according to 
Churchill, is embodied as the complex socio-political, economic and militaristic kinship between Great Britain and the United States. This kindred relationship serves as the foundation for a new global community and, eventually, “... the principle of common citizenship" (Ibid.: 7) opposing the “... expansive and proselytizing tendencies” of Soviet Russia (Ibid.: 8). In his speech, Churchill emphatically notes that "from Stettin in the Baltic to Trieste in the Adriatic, an iron curtain has descended across the Continent" (Ibid.: 9) beyond which a multiplicity of evil and wrongdoing occurs. No doubt, somewhere in Soviet Europe a leading voice was concurrently expounding similar views of the West to his people. Churchill's oratorical mastery nevertheless reflects one way in which impermeable ideological barriers are framed and constructed. 


\section{CHAPTER 3 - SYNTHESIS}

\section{HUMAN MOBILITY AND THE NATURE OF BORDERS}

So, what does the literature tell us about the cultural underpinnings of border building, especially in the context of, as well as vis-à-vis, the human biological tendency to move? For the human species, with its constant drive to migrate into and place its roots deeply within nearly every ecological niche of our planet, the building of barriers seems somehow unnatural, often counterintuitive. Yet, construct walls humans do. Over a long expanse of time, humans have developed cultural biases for wall-building that counteract this innate urge to keep ourselves and our ideologies mobile. We build walls for a variety of reasons, all emanating from growing neurocognitive abilities that have allowed for and facilitated the development and evolution of complex culture. Once it is established that wall-building is a derivative of emerging human culture, it is logical to then attempt to understand and outline the specific motivating factors that drive humans to build walls. That is, what are the essential elements of the human penchant to carve out boundaries and construct borders that impede our mobility - a mobility that is significantly more ancient than the cultural origins of wall-building?

Amanuel Beyin (2015), Paul Mellars (2006) and Mary Stiner (2002) assist us in

understanding the rough brushstrokes of the bigger-picture migrational patterns of early humans, while Peter Bellwood (2013), Susan Antón (2004) and DongJu Zhang (20126) contribute the finer details of human archaeologic and DNA patterns that support such 
demographic mapping. Together, these authors draw increasingly distinct pictures that depict the migratory roadmaps humans and their forebears have followed over the deep history of time. Additional writers, including Merlin Donald (1991) and Steven Pinker (2010), tell us that at some point the biological drive to move was increasingly influenced by evolving cultural biases that were, in part, a result of the human brain emerging into a more highly efficient cognitive machine. Thus, the combination of cultural bias and expanding cognition resulted in humans engaging in more complex boundary-building behaviors. Furthermore, Tuomas Forsberg (2003), Jonathan Haidt (2012), Setha Low (2009) and Robert Sack (1986) address the foundational elements of building walls including the management of fear and the unknown Other, the expression and implementation of biological and social power, the ability to create additional structure and stability in chaotic environments, and the facilitation of the allocation of limited resources amongst diverse populations with various needs and desires. Still others, like Adrian Goldsworthy (2018), Ian Haynes (2014), Anne Applebaum (2013) and Edith Sheffer (2011) describe the origins and construction of Hadrian's Wall and the Iron Curtain examples of the physical and ideological barriers, respectively, that are the end-products of such culturally-driven behaviors.

Once the broad issues surrounding the topics of mobility and boundary making have been distilled and a series of inferences derived, we are better able to more clearly define a general theory of human wall-building, which is the intention of this thesis project. Through a review of the available literature, what seems evident is that a clear, general theory of these particular behaviors is not a result of any single explanation as most literature seems to suggest. Rather, the cultural phenomenon of wall building is 
multifactorial and, therefore, best understood and explained by offering a handful of interrelated elements that consistently contribute to such behavior. Henceforth, I propose that a novel general theory of human wall-building, based upon an array of elements at its core, can be outlined and articulated. Entitled the S-ential Theory of Human WallBuilding, this theory describes the five essential components that lie at the foundation of our species' tendency to construct walls. These defining elements - separation, structure and stability, symbolism, social skin and society building - are, in varying degrees, at the root of, and can be identified in, all human wall-building projects. An analysis of each element's role in such behavior allows for improved clarification into the motivations that compel humans to build walls of varying typologies across time.

Finally, once this S-ential Theory of Human Wall-Building is described, I undertake a comparative analysis of two distinct historical walls, Hadrian's Wall and the Iron Curtain, to examine whether the construction of these walls validates the basic tenets of this new theory. Do these specific walls, lying at disparate ends of two separate continua (the temporal and the physical-ideological) support such a generalized theory of border building? That is, can the consistent threads of wall-building, as expressed in this theory, be identified in walls, like Hadrian's Wall and the Iron Curtain, that are of distinctly differing typologies, as well as ones that were constructed nearly two millennia apart? Once this theory is successfully applied to the selective analysis of Hadrian's Wall and the Iron Curtain, then its application in supporting the construction of additional walled projects can be undertaken in further analysis by other investigators. 


\section{THE S-ENTIAL THEORY OF HUMAN W ALL-BUILDING}

This original theory of wall-building can be distilled into five motivating triggers the whys at the foundation of all human boundary-making endeavors. Across time, both physical and ideological walls incorporate, to varying degrees, the elements of separation, structure and stability, social skin, symbolism and society-building. Thus, these elements are the constitutive S-ences of human wall-building. While each of the components fundamentally differs from the others, they are nevertheless intimately connected and mutually inclusive in that they all emanate from a common source - that is, each of these factors is a response that has evolved over time in feedback to the human need to control perceived vulnerabilities and to import additional order and stability to the dangerous and fragmented environments in which they live. The building of walls has served our species well, providing a culturally-derived evolutionary advantage, and has played a pivotal role in the relative success of Homo sapiens vis-à-vis all other species of the animal kingdom.

The S-ential Theory of Human Wall-Building states that the human species builds boundaries across both typology and time in order to accomplish the following goals:

- To effectuate its need to create separation from perceived acute and chronic threats.

- To provide additional structure and stability in chaotic environments through mechanisms of spatial and temporal compression, as well as to furnish the infrastructural building blocks for cohesive processes to occur at borders.

- To express implicit and overt symbolic messaging.

- To allow for the emergence of zones of cultural fusion and translocation through the provision of a semi-permeable social skin.

- To facilitate the reinforcement of societal status quo within the society constructing the boundary. 
While every wall is unique, each of these foundational elements exists, in various degree and overlay, at the foundation of the imagination, construction and sustention of all humanbuilt walls.

\section{THE S-ENTIAL THEORY - DisCuSSING THE FIVE S'S}

\section{SEPARATION}

Unquestionably, the most common interpretation as to why humans construct barriers is that they do so in order to separate the "self" from the "other", or, rather, to keep at bay the often unforeseen, barbarous savage. That this is the case is a function of the earliest of the foundational elements of wall-building to emerge, that is, the critical, visceral need to devise boundaries as spatial buffers. Such buffers were first established in order to separate humans from other animals as a mechanism for both controlling fear and simply increasing the likelihood of survival. Trout (2011) describes the visual imagery necessary to transport the reader back to a danger-filled hominin deep history. One need only imagine the savage take-down of a gazelle by a hungry lioness on the Serengeti plain, or hear the shrieks of a fowl in the firm grasp of a red-tailed hawk, to acknowledge the surety of the natural perils that our hominin ancestors faced in their constant struggle for survival. As mechanisms of conceptualizing buffers between harm and security, the most primitive forms of physical and ideological boundary building must have occurred long ago as our increasingly mobile (and, relatively defenseless) forebears balanced their drive to remain mobile with their desire to experience the next day.

The earliest imaginary boundaries conceived by the primitive human brain likely evolved from the capacity to meld pre-lingual mimetic communication into archetypal systems that allowed for the intra-group dissemination of information shielding pre- 
modern humans from the dangers that constantly lurked about them. Those groups that utilized such tools most optimally would be the likeliest to survive in such a perilous environment. Thomas Suddendorf (2013) writes of the emerging behavioral flexibility that endowed the evolving hominin with this additional edge to compete. Such communication would constitute the basic cognitive armamentarium needed to construct these early protective warning systems - a prototype for more elegant future physical and ideological walls. With the emergence of more highly developed human cultural forms, these embryonic non-structural buffers would eventually give rise to more well-defined barriers of both a physical and ideological nature.

Intimately tied to such archaic fear management strategies is the continued presence of Othering behaviors chronically exhibited by our species. Why do such boundarypromoting practices linger? Based upon his inferences of the connections between Pleistocene and post-Pleistocene social structures, H. Martin Wobst (1974) notes that via assigning territorial limitations between themselves and threats of various sorts humans promote the likelihood of biological and cultural proliferation. This process of Othering, in the view of Yuval Noah Harari (2015), allows humans to maintain material and subjective compartmentalization through the establishment and reification of imaginary orders. Such compartmentalization is crucial in that, through such a process of environmental differentiation, humans are able to manufacture and apply the social glues that bond themselves with their groups. This, of course, results in a positive feedback loop - that is, the establishment of a safer environment innately tied with the promotion of an enhanced state of social cooperation. 
Once humans more firmly establish their ability to hold their own against vicious predators they encounter in primal harsh environments, they could cooperate to develop physical walls that would provide them spatial buffering from additional potential harms (for example, the weather; the opportunity to divide limited spatial schemes in order to further define intragroup social responsibilities, such as food gathering and preparation; or, to accommodate members within increasingly complex group structures with mechanisms of privacy and sequestration based upon social hierarchies.) Steven Kuhn (2009) writes of one of the earliest human walled structures, Ucagizli Cave, as an example of intentional modification, compartmentalization and separation of human structures resulting from the need to clarify distinctly evolving roles in social groups. In his research, Ian Kuijt (2000) also recognizes that increasing social complexity necessitated physical boundaries for separation within enlarging groups in order to ensure privacy and control over the allocation of resources. The notion of contained, walled African communities, as described by James Tracy (2000), gives credence to the necessity of $10^{\text {th }}$ century BCE peoples to recognize the importance of barriers in the provision of additional layers of buffer between marauding neighbors, as well as animals posing a threat to their livestock or themselves. In the same light, Jared Diamond (1997) acknowledges that major architectural innovations, such as multi-storied buildings, are introduced as social stratification becomes increasingly complex in the periods marking the transition from small egalitarian bands to larger and more hierarchical human groups.

\section{STRUCTURE AND STABILITY}

Related to their ability to provide buffer zones of safety from immediate threats, borders also allow for the creation of structure and longer-term stability in chaotic 
environments, independent of any acute danger. As evolving cultures make the transition from small groups to those with the recognizable traits of an emerging society, the capacity of barriers to provide spatial structure becomes increasingly relevant. Borders contribute to such intermediary processes in two distinct ways. First, through their ability to compress spatial and temporal dimensions in border areas, barriers dampen, or bring an order to, the frenetic chaos that is naturally expected at alien interfaces. Second, borders and their associated zones of hybridization, created through such spatial and temporal compression and deceleration, provide a sort of retinaculum upon which those responsible for slowing can further interact with those that are slowed. Precisely through the control of spatial and temporal dimensions on the periphery of borders, those that imagine and construct walls establish the initial frameworks that serve to allow the processes of cultural fusion to occur. It is in these spaces that unique hybrid culture and novel place often unintentionally develop. In this way, borders serve as both the agar plate and the enzymatic catalyst for further group cohesion and amalgamation. Anne Jensen (2011) writes about the seeming inherent contradictions of a widely-ranging, mobile human population being mandated to slow, and even cease, their movements as they weave within and about the thickened spatial resistance of border areas. Such contradictions provide opportunities for the cultural bricolage that allows for the cross-breeding of people and their ideologies.

The addition of structural templates in such chaotic settings should not be presumed to necessarily beneficial in nature. In her work on Israeli-Palestinian strife, Julie Peteet (2017) highlights the function of walls to contribute to the groundwork for such structure building, albeit negatively so. Viewing such 'opportunities' in a different light, Peteet describes the slowing of spatial, temporal and directional dimensions at border zones as 
ambiguous, and that such ambiguity conveniently provides nothing more than a robust mechanism for further state control of a disempowered population. While the wall in place between Israel and occupied Palestinian territories lessens the opportunity for fractious exchanges between these two populations, it does so at significant costs. Those costs include that of denying Palestinian populations agency in determining their futures, as well as the creation of what Javier Auyero (2012) refers to as relegated spaces (homes, camps and lands), thus amplifying an evolving state of Palestinian subjugation and victimization. An additional example of the ability (and inevitability) of barriers to negatively affect disordered environments is underscored in Theresa Singleton's (2001) research of $18^{\text {th }}$ century Cuban coffee plantation slaves. The combination of barracones (celled housing) and the surveillance of slave space through a means of vertical surveillance, or panoptics, disallowed the enslaved population from allocating normal spatial and temporal dimensions to their daily lives, thereby thwarting the flow of their bodies and ideologies. Such cessation of free movement mandated a forced fusion of the enslaved population, with the inevitable outcome of hybrid cultural forms.

\section{SOCIAL SKIN}

Once it is established that humans need to both separate themselves from others and to create further structure that dampens the degree of chaos in uncertain environments, it becomes more apparent that mechanisms must exist for a barrier to communicate with and allow for translocation with the opposite side. With the establishment of boundaries that separate human groups, there is a requirement for a means of transitioning outsiders, and their goods and ideas, from one side of a boundary to the other. The formation of semipermeable barriers allow for such translocation to take place in border zones, facilitating 
the controlled movement of people and their ideology across such barriers. The existence of borders with graded porosity allows for opportunities of cultural hybridization of differing people and cultures. In this way, semi-permeable borders allow for the safe, measured integration of Others into an alien polity. The creation of hybrid transitional zones promotes stable processes of assimilation and multiculturalism, or, rather, via its functioning as the social organism's dermis (it's outermost protective layer) borders bolster a controlled process towards a state of higher cultural entropy or homogeneity.

In his analysis, David Newman (2003) appreciates the function of walls to offer the builders of borders some degree of protection from the infiltrative practices of an alien minority. While offering impediments to foreign ideology, borders simultaneously create points of interface between exotic cultures. It is through the interface of differing ideologies and cultures that new notions of culture originate and are translocated in modified forms more readily acceptable by those of differing lifestyles and viewpoints. According to Setha Low (2009), it is the unusual combination of protection from and connection to the alien world that leads her to use a term that combines biology and culture to describe the walls we build - that is, humanity's social skin. Michel Foucault (1986), too, uses a biologic metaphor when he notes that human sociability is akin to "a network that connects points and intersects with its own skein" (Foucault, 22). Further, Toumas Forsberg (2003) utilizes language such as "filters" and "crossing points" (Forsberg, 11) in describing one of the integral roles played by human bordering processes. Suzanne De Atley and Frank Findlow (1984) urge caution in applying the analogy of a social dermis to humans. They suggest that the more proper metaphor for societal skin (which allows only one-way movement) is that of the semi-permeable membrane (which allows bi-directional movement.) While 
simple organisms have true bodily margins beyond which their substance cannot move in multiple directions, the highly mobile human species is constantly attempting to procure new, multi-directional territorial margins. In his work, Newman (2003) concurs with this view as he describes borders as possessing various degrees of permeability. Thus, it is semi-permeable borders that permit the graded trans-boundary movement of humans, their goods and their ideological capital through their capacity to simultaneously impede movement and to create points of interface.

\section{SYMBOLISM}

The most overt function of boundary making in our modern world lies in the ability of physical and ideological walls to express symbolic meaning by those that create and manage them, as well as by those that are susceptible to their interpretations. While physical barriers reflect symbolic intent through their materiality, ideological walls are mediators of symbolic imagery through implied meaning, lexicon and signage. Both types of boundaries attain symbolic significance through what Yuval Noah Harari (2015) describes as the concept of "artificial constructs" that allow groups with common belief systems to convey ideas through commonly accepted imagery. That is, the capacity and value of borders to exert power through such imagery exists in the fact that the human species is unique in its belief in myth. Generally speaking, humans accept borders and border symbolism, whether of material or non-material form.

Ideological barriers exert their symbolic meanings in myriad non-material ways. As an example, Reece Jones (2016) relates the presence, or mere threat, of uniformed police or military troops on borders as being potently symbolic in its ability to portray border zones as war zones and, therefore, zones to be avoided. In her essay on mobility and 
space, Anne Jensen (2011) alludes to the symbolic power of barriers to shrink time and space not in an effort to tame the chaos of border zones, but rather to intentionally subjugate populations through imagery of both the real and imagined exertion of biopolitical power.

It can be challenging to clearly understand the intent of ancient symbols as they are always interpreted through a contemporary lens and context. Tim Ingold (2005) suggests that material objects are simply surrogates for cultural concepts and, as such, that symbolic imagery is place-bound. Therefore, the true meaning of any symbolic image is entirely contextual and, thus, can only be interpreted in the space and time in which it was originally spawned. As such, modern interpretations necessarily make assumptions about ancient intent. Furthermore, the degradation of symbolic materialities over time often hinders one's ability to completely appreciate the motives and objectives of those constructing ancient barriers.

\section{SOCIETAL STATUS QUO}

The least ancient of the essential elements driving humans to build walls of various typologies is a boundary's ability to establish a strengthened polis ${ }^{2}$ or community through the reification of preexisting status quos of the society building the barrier. The construction of both physical and ideological barriers is often utilized to solidify existing power structures, as those responsible for building walls do so, in part, to maintain the balance of power in their favor. With the demarcation of physical and ideological borders, an enhanced sense of common cultural purpose and the resultant reification of existing hierarchical relationships within the affected community is reinforced. For those responsible for the barrier's construction, wall building augments the sense of polis closer

\footnotetext{
${ }^{2}$ Polis is a word of Greek origin and is generally translated as meaning 'city 'or 'body of citizens.'
} 
to home, though home is often located a significant distance from the wall. Boundary projects fortify the sense of community in the wall-building society by reinforcing the critical nature of establishing borders in order to separate core populations from real or imagined dangers found in the more peripheral zones. Through their symbolic imagery and associated rhetoric, walls are exquisitely capable of fueling the fires of public emotion. In a contemporary context, Nicholas de Genova and Nathalie Peutz (2010) discuss such responses to border insecurity as a mechanism of substantiating “... national control over space and territory” reifying “... political, racial and class-based boundaries” (De Genova and Peutz, 4).

Through the manipulation of such Othering processes, the power elite are permitted to continue to allocate political, economic and social resources to those they favor. In such a manner, those who imagine and construct walls do so, in part, with an intentional objective to further stratify and order the population into distinct social classes within the wall-building society. Referring to the connections between walls and society-building, Tim Cresswell (2001) describes the purposeful restraint of human mobility through the placement of demarcated boundaries as an attempt to exert biological power in order to more clearly secure social stratifications within a larger group. Reece Jones (2016) concurs as he examines the use of borders as coercive tools in a society's desire to maintain the status quo of existing societal hierarchies and its attendant power relationships.

\section{A COMPARATIVE ANALysis OF Two Distinct Walls}

HADRIAN'S WALL

Both ancient and of colossal proportions, Hadrian's Wall once rolled unbroken some eighty-plus Roman miles (seventy-three miles) across the breadth of northern 
England's early $2^{\text {nd }}$ century landscape. The barrier bounded Britannia at its isthmus, cutting the island into a north and south - as it ran from Wallsend on the River Tyne in the east to Bowness-on-Solway on the Firth of Solway in the west. ${ }^{3}$ Commissioned by Roman Emperor Hadrian in $122 \mathrm{CE}^{4}$ to guard the Empire's northwestern-most frontier, Hadrian's Wall was built less than half-a-generation's time through the toil of three legions, some 15,000 members, of the Empire's citizen army. In its original and modified plans, this hardened wall consisted of a highly organized system of component pieces designed to impede and control the flow of humans, animals, weaponry and trade between Britannia's barbarous tribal north and its tamer Roman south.

While the reasoning at the root of any imperial mandate that commanded the construction and long-term occupation of Hadrian's Wall ${ }^{5}$ over the nearly three centuries of Roman dominion in Britain remains arguable, past extensive archaeologic efforts give us a more lucent understanding of this barrier's design and essential structural elements. At the core of the Hadrian Wall complex is the curtain wall, the typical walled structure commonly visualized when thinking of this barrier. Built in an east-to-west direction starting at the Tyne, the proximal fifty-three Roman miles of the Wall were constructed of stone; the distal thirty-one Roman miles on toward Bowness-on-Solway of turf and timber.

\footnotetext{
${ }^{3}$ See Appendix, Image 1 - Roman Britannia depicting the extent of Roman Britannia and Image 2 Hadrian's Wall Route illustrating the mid- $2^{\text {nd }}$ century route of Hadrian's Wall with its associated major wall forts and confederate outposts.

${ }^{4}$ Initially, Hadrian's Wall was constructed over a period of about six years, though subsequently the wall underwent numerous reconstructions and modifications throughout its Roman tenure.

5 While occupied almost continuously through the early $5^{\text {th }}$ century, Hadrian's Wall was temporarily abandoned in $142 \mathrm{CE}$ for a brief period of time as Hadrian's successor, Antonine Pius, ordered the construction of the Antonine Wall. Antonine's wall, about half the length of Hadrian's, was located further north in southern Scotland where the Romans were attempting to establish a new frontier. That wall also ran sea-to-sea, but across the Scottish isthmus - from the Firth of Forth in the east to the Firth of Clyde in the west. The Antonine Wall was occupied for a mere twenty years, eventually being abandoned as Roman troops reoccupied Hadrian's Wall in 165 CE.
} 
Over the course of several subsequent decades, the entirety of the wall structure was converted to stone. The curtain wall consisted of several key facets - a simple wall, turrets, milecastles [or fortlets], larger forts and gates. Beyond the curtain wall lay the other units of the Wall complex - a service road running generally parallel to Hadrian's Wall to its south, as well as a system of defensive berms and ditches to both the curtain's north and south.

The curtain wall measured three to six meters in width and some four meters in height. Generally, sections constructed of stone were some three meters wide, while if made of turf and timber the Wall required additional width for further stability. ${ }^{6}$ At onemile intervals along the curtain's length stood a milecastle, a small fort (fortlet) housing up to eight soldiers, each milecastle with an accompanying pass-through gate. Between milecastles were two turrets evenly spaced one-third of a mile apart. Turrets allowed for several additional men to be housed, as well as improved the ability for more optimal visualization of the areas beyond the vicinity of the wall. Interspersed along the entire length of Hadrian's Wall, at approximately seven mile increments, were larger forts garrisoning a substantially larger battery of Roman infantry, cavalry and their horses.

Hadrian's Wall was erected along a route that more-or-less followed the line of an earlier Roman construction, the Stangate or stone road. ${ }^{7}$ This roadway had been in use for at least several decades prior to the construction of Hadrian's Wall. ${ }^{8}$ With the building of Hadrian's Wall, the Stangate served as a mechanism of efficiently moving troops along the

\footnotetext{
${ }^{6}$ The stone walls were built from locally-quarried sandstone and limestone and were comprised of a rubblecore with smooth stone facings.

7 Translation from Old Norse

${ }^{8}$ A Roman presence in Britannia was first documented in 55 BCE when the Roman general Julius Caesar invaded Britain from Gaul.
} 
breadth of the structure in order to acutely supplement manpower, when needed, or as a means of additional logistical support. Running the full length of the southern face of the barrier, and just to the north of the Stangate, was Hadrian's Wall vallum, a combination of a ditch and multiple earthen berms capable of slowing human or animal movement in either direction. Together, the Stangate and the vallum served as the functional elements of the southern perimeter of the Wall's complex. Just north of the curtain lay a large V-shaped ditch, some five to six meters deep and almost as wide. Easily traversed by crossing paths located at each milecastle, this defensive ditch was otherwise difficult to expeditiously navigate whether on foot or horseback. From north to south, the entirety of the structural complex was well over one hundred meters deep. ${ }^{9}$

Supporting Hadrian's Wall on its outlying northern and southern margins were numerous other large forts used to warn of brewing troubles among the various Scottish tribes in Roman territory to the structure's south. In the far west, non-curtain wall components of Hadrian's Wall, including towers, fortlets and forts, extended another twenty-five miles beyond Bowness - snaking further south along the Cumbrian coast as additional protection against enemies who might attempt to flank the curtain by sea.

Formally abandoned by Rome in $410 \mathrm{CE}$, as imperial policy-making moved the Empire's northernmost frontier back to the continent, Hadrian's Wall declined into a centuries-long period of neglect and disrepair, its stone confiscated by local farmers, villagers and clergy for the construction of field walls, houses, farm buildings and churches

\footnotetext{
9 One of the functions of Hadrian's Wall was to address Roman concerns of disgruntled, trouble-making Scottish tribes from moving southward into imperial territory. But, the imperial government also invested considerable energy in making sure that rogue bands successful in invading and pillaging territory south of the wall had considerable difficulty moving their newfound plunder in a northerly direction on their journey home. Thus, the Hadrian's Wall complex was designed with impediments to movement on both its southern and northern faces. See Appendix, Image 3 - Hadrian's Wall Schematic and Image 4 - Hadrian's Wall Schematic (Aerial View) for views of the wall's design.
} 
and its remaining turf and timber components disintegrating to the vagaries of Mother Nature. Serious scientific interest in Hadrian's Wall began in the early $18^{\text {th }}$ century, while intensive archaeological investigations into its remains evolved in the early-to-mid $19^{\text {th }}$ century. Contemporary imaging techniques facilitate the continuing study of residual subterranean segments of the complex, thus allowing for an even more illuminating realization of one of human history's most remarkable architectural creations.

Hadrian's Wall is a material wall built nearly two thousand years ago in the hinterlands of a massive empire. Despite its significant distance from the center of Roman power, this structure was built with the deliberate intent to fulfill the needs of a strategic and supreme emperor. Through an analysis of the perceived imperial need for such a structure, as well as its design, construction and multi-century occupation, this engineering project proves to be an ideal example of the reasons why humans are compelled to build such physical barriers. Hadrian's Wall checks all the boxes of the foundational elements of the S-ential Theory of Human Wall-Building. The structure's purpose and function are reflections of the five essential criteria at the core of explaining such endeavors in that Hadrian's Wall provides a means to separate alien tribes and cultures, affords enhanced stability and structure in the turbulent Roman frontier, possesses a social membrane around which hybrid populations fuse and translocate, generates symbolic meaning through its physical materiality and coupled imagery, and promotes the further development of community and existing status quos in the Roman society responsible for its construction. HADRIAN'S WALL-SEPARATION

The Roman imperial frontier was a treacherous environment. Inhabited for many centuries by tribes of Celtic origin, among them the Novantae, Selgovae and Brigantes, 
allegiances in this region were fragile and scores were settled with fist and sword. In $2^{\text {nd }}$ century Scotland, the native populace was quite poor and possessed a paucity of resources. There, struggles to survive were significant and encountered on a daily basis. As Roman influence expanded northerly towards the isthmus of Britannia, the lure of Romans and their relative wealth must have been a constant attraction to the destitute Scots. The resultant threat to the Roman legionnaires and their families, as well as the risk of exposure to their animals, possessions and tradeable goods was acute and constant. Thus, first and foremost amongst the many purposes of Hadrian's eponymous architectural stalwart was its ability to separate and defend its soldiers from the Celtic clans to its north. Eighty Roman miles of timber, stone and mud kept the Roman population and their entourage relatively safe by decreasing the frequency and intensity of marauding intruders, thereby allowing the imperial force the ability to secure their purposeful occupation. Furthermore, Hadrian's Wall, as an occupied stone and timber structure, provided a physical buffer between its inhabitants and the harsh climate of the northern latitudes. While formal villages were an ever present part of the Wall's perimeters, it was the structure's fortlets and milecastles that were primarily responsible for cushioning the occupying soldiers and their horses from the dangers of the frigid Britannian winter.

\section{HADRIAN'S WALL-STRUCTURE}

The period of the $2^{\text {nd }}$ to early $5^{\text {th }}$ century Roman occupation of Hadrian's Wall provided several examples of its ability to furnish a retinaculum that allowed for the tempered physical and ideological binding of the component parts the varied Roman peoples (southern Europeans, Germanics, North Africans and those from the Levant, for example) and their cultures as they intermixed in this frenetic region. In the most literal 
sense, Hadrian's Wall was a physical structure occupying a large space and constructed of voluminous materials. Simply by its presence, Hadrian's Wall served as the nidus for a host of material infrastructure that accommodated not only a large population's basic needs for shelter, defense and sustenance, but also, by serving these necessary functions, allowed for the matrix upon which cultures interfaced. Ultimately, any given barrier's capacity to facilitate a template upon which people from various cultures can meld in a semi-restrained fashion is a function of its ability to compress both space and time. In this way, Hadrian's Wall provided the medium that permitted such cultural amalgams to establish themselves and, subsequently, thrive.

The native population to the north of the wall and the occupying one south of it differed in fundamental ways. The Scottish tribes were Celtic in origin and, therefore, largely adhered to a common paganism in their spiritual belief systems. The clans were governed via fragmented, loosely constructed tribal systems of leadership and were, in general, desperately poor. On the other hand, while the term 'Roman citizen soldier' may have implied a Latin origin, this was hardly the case. South of the Wall, the Roman occupiers were an olio of people whose cultures were varied and whose idols were culled from an assortment of theistic belief systems. A composite of citizen soldiers, slaves and their families came to the northern imperial frontier from across the Roman Empire. They came from North Africa, the Levant, southern and central Europe, and throughout the Iberian Peninsula. These peoples spoke myriad languages and dialects particular to regions within regions and, with them, they brought a panoply of foods, clothing and personal adornments. The literature is replete with examples of the resultant hybrid cultures that were established at the Wall's southern periphery as these populations fused. Archaeologic 
evidence, as outlined by Ian Haynes (2014), David Breeze (2006) and Brian Dobson (2000), describe clothing styles, foodstuffs, jewelry, governance structures and theisms that appear original and unique to the Wall's border zones, suggesting the expected amalgam of differing cultures that evolve when humans live among one another for extended periods of time.

Ian Haynes, Nicholas Howe (2005) and Richard Muir (2000) inform us of the realities of becoming a blended citizen of the Roman Empire in the context of a multinational and multicultural frontier. Haynes, through his comprehensive excavations of Hadrian's Wall and its supporting structures, finds clear archaeologic evidence that the intermingling of multiple cultures led to the appearance of new hybrid populations along its southern border, thus redefining the meaning of what it meant to be a citizen of the Roman Empire. Howe writes that Hadrian's Wall proclaimed, and as such served as a surrogate for, these newly formed relationships between the colonized and the colonizer, while Muir addresses the significance of this hodgepodge of people reorganizing their cultural systems "within [these new] superimposed networks of overlapping authorities" (Muir, 75). Due to a paucity of archaeological evidence, we know relatively little of the composite cultures that may have evolved north of Hadrian's Wall. Almost certainly, Scottish clansmen and Roman soldiers would have intermixed and formed alliances for the purposes of trade and protection, at the least. Beyond that, there probably existed a degree of interbreeding and the development of more formal kinship affiliations that resulted in some forms of new Scottish-Roman cultural prototypes. 


\section{HADRIAN'S WALL-SOCIAL SKIN}

Hadrian's Wall fulfilled its role as the Roman Empire's social skin on the imperial northern frontier. The barrier's architectural design literally incorporated the brick and mortar analog of dermal pores with the calculated placement of secure timbered gateways in its many fortlets, milecastles and forts. In this way, the Wall could offer both vital protection to those in service to the Wall and controlled movement across it. In the case of Hadrian's Wall, the structure's provision of a membranous border made of stone, turf and timber through which people, as well as their possessions and ideas, were translocated is perhaps the ideal historical representation of a frontier boundary serving a vital role as societal skin.

HADRIAN'S WALL-SYMBOLISM

Its ability to overtly express rich symbolic imagery stands not only as one of the richest legacies of Hadrian's Wall, but, arguably, as the most fundamental reason behind its conceptualization and construction. The structure exuded its dense symbolism in both objective and subjective ways. Objectively, the sheer physicality and materiality of the wall was certainly an extraordinary presence on this $2^{\text {nd }}$ century landscape. Roman mile-afterRoman mile of stone and timber along the rolling, cragged heaths communicated plain and subtle messaging to those viewing from either the south or the north. Brent Sterling (2009) interprets Hadrian's Wall and its Roman tenant soldiers as having dual symbolic intent (militaristic and psychological) in that the Wall served to remind invading forces of both the consequences of deterrence by retaliation and deterrence by denial that might result from any potential foray beyond the structure's protected face. On the other hand, Adrian Goldsworthy (2018) denies that the primary intent of Hadrian's Wall was ever meant to be 
one of defense. Instead, Goldsworthy focuses on the Wall's two main symbolic objectives, that of a conspicuous visual representation of Roman strength and, more subtly, as an indicatory nod towards home that the expansionary, multi-front policies of the empire, aggressively pursued by Hadrian's predecessor, Trajan, were coming to an end. In the latter case, Hadrian was deliberately implying that with the Wall's construction the Roman Empire was ceasing to expand into territories beyond it. That is, Hadrian, partially by virtue of his Wall and other significant artistic and architectural endeavors, emphasized peace and fiscal prudence over aggressive and unlimited territorial expansion.

Jarrett Lobell (2017) interprets the symbolic meaning of Hadrian's Wall through its existence as both an artistic and architectural project. Hadrian was of Greek heritage, thus he was raised and educated in a manner that emphasized the role of culture, not aggression, as the most vital ingredient of a healthy, vigorous society. At home and abroad, Hadrian hoped that his subjects' interpretation of his leadership skills was heavily influenced by his intent to further enhance Rome's reputation through the support of great artistic and architectural programs, as opposed to military expeditions. In his interpretation of the symbolic significance of Hadrian's Wall, Robert Witcher (2010) dwells on the issue of historical context in the interpretation of symbols, and this point is key to appreciating the nuance of symbolic imagery in the example of Hadrian's Wall. Witcher, along with Claire Nesbitt and Divya Tolia-Kelly (2009), accedes that symbolic materialities are always interpreted through a contemporary lens. In that way, the symbolism of this structure is alterable as perceptions of it vary through the eyes and emotions of the interpreter. So, while $2^{\text {nd }}$ century Scottish tribes were inclined to view the Wall as a symbol of Roman strength, a late- $20^{\text {th }}$ century British citizen is just as likely to equate the term Hadrian's 
Wall as a brand representation of northern England's commitment to the production of sturdy, reliable commodities.

\section{HADRIAN'S WALL - SOCIETAL STATUS QUO}

The realities of Hadrian's Wall effectuated the evolution of a more stable frontier population at its periphery, while, at the same time, enhancing existent societal class stratifications at the Roman imperial core. Using Hadrian's Wall as a massive works project, the ruling Roman elite appeased the frontier masses by keeping a significant portion of its populace employed, fed and housed. Such logistics were realized through governance structures rigidly hierarchical in nature, with power emanating from Rome outward and transferred to layers of governors and lieutenants located in the frontier. Such formal governance increased the likelihood that frontier policy was consistent with supporting the imperial status quo at home. Through positing Hadrian's Wall as a defensive mechanism against the savage Scottish tribes to its north, Hadrian and his governing partners could assure the Roman people of some degree of safety and security at home and abroad. In addition, by embarking upon a platform of anti-expansionism, fiscal prudence and the pursuit of monumental art and architecture, Hadrian best assured the continued legacy of both his Empire and royal court. Both tacks served to bolster Hadrian's prospects of maintaining harmony within the status quo that existed in central Rome.

\section{THE IRON CURTAIN}

With the defeat of fascist Nazi Germany in the spring of 1945, Europe was partitioned amongst the Second World War's victors - the United States, the United Kingdom, their European allies and the Soviet Union. Initially, from 1945-1952, the earliest years of the post-World War II cold war, the Iron Curtain was drawn as a soft or 
ideological line ${ }^{10}$ dividing those nations that won the grim, deadly conflict from those that lost it. The newly acknowledged line defined the separation of the countries of western Europe from those of eastern Europe, thus delineating two starkly contrasting cultures, one established within the framework of an economic system of capitalism and liberal democratic ideals and the other based upon socialist economic principles driven by a Soviet totalitarian regime. Persisting for some four-plus decades, until the eventual collapse of the Soviet Union in 1991, the Iron Curtain spanned "from Stettin in the Baltic to Trieste in the Adriatic..."11 serving to functionally isolate the European puppet ${ }^{12}$ countries (East Germany, Poland, Hungary, Czechoslovakia, Yugoslavia, Romania, Bulgaria and Albania) within the sphere of influence of the Soviet Union from those countries under the sway of western Europe and the United States.

The Iron Curtain was comprised of a spectrum of boundary typologies, from the purely ideological to soft, green borders ${ }^{13}$ to fully hardened physical barriers. The metaphor of an iron curtain was utilized to describe this boundary in order to reflect its essence, that is a substantial barrier that was impermeable to the flow of ideology. ${ }^{14}$ Once conceptualized

\footnotetext{
${ }^{10}$ Israeli historian Yuval Noah Harari describes nation-state borders as prototypical of the supposition of artificial constructs - that is, like legal systems, currencies and religious organizations, among other examples, such borders are figments of our imagination and exist only because of the value placed in them by humans. The allied victors, led by Franklin Roosevelt, Winston Churchill and Joseph Stalin, agreed in principle to one such construct with the post-World War II division of Europe at the Yalta Conference in February 1945.

${ }^{11}$ From Winston Churchill's Iron Curtain Speech given on March 5, 1946 at Westminster College in Fulton, Missouri. While Churchill described the Iron Curtain as extending from the Polish coast on the Baltic Sea to Trieste, in far northeastern Italy, on the Adriatic Sea; in fact, the barrier continued even further north dividing the Soviet Union from the Scandinavian states. See Appendix, Image 5 - The Iron Curtain to reference mapping of the Iron Curtain.

${ }^{12}$ The term puppet is derived from these countries being controlled by a marionette government in Moscow.

${ }^{13}$ The term green border derives from historical borders demarcated primarily by topographic landmarks such as rivers, rock formations and trees.

${ }^{14}$ See Appendix, Image 7 - The Iron Curtain Metaphor to better sense the satire used to depict this ideological barrier.
} 
and mapped, the barrier was steadily materialized over its mid-to-late $20^{\text {th }}$ century lifespan. Thus, by the culmination of the fall of the Soviet Union and its eastern bloc satellites, the Iron Curtain had evolved into a more traditional hard border of concrete, guarded border crossings, barbed-wire and land mines which severely limited the movement of humans and goods in either direction. Yet, it is the subjective, or more intellective, component of the earlier wall that is of special interest in this thesis.

The Iron Curtain existed on various scales. Within the broader trans-European Iron Curtain, ${ }^{15}$ the German portion of the protracted barrier, the inner German border, ${ }^{16}$ separated the Federal Republic of Germany [FRG] (democratic West Germany) from the German Democratic Republic [GDR] (socialist East Germany). Along the breadth of the intra-German border are examples of people of common, longstanding cultural heritage being divided by an arbitrarily-placed barrier between long-neighboring towns. Often evidenced only by topographical markers, boundaries at many locations continued to allow the relative free-flow of humans and capital, at least during the early post-World War II years. Yet, despite the movement of people back and forth, clear ideological chasms, born of a gradual escalation in cultural, political and economic isolation, began to form between those on opposing sides of the boundary line. An analysis of the Iron Curtain, on both towntown and broader state-state scales, adds additional insights to the human ability to create stout ideological barriers, even as such barriers remain relatively permeable to human movement.

\footnotetext{
${ }^{15}$ This lengthier trans-European barrier extended some 1,393 kilometers [866 miles] from the Baltic Sea to the Czechoslovakian border in the south.

${ }^{16}$ See Appendix, Image 6 - Inner German Border. This map allows one to visualize that the Iron Curtain completely divided greater Germany into two halves. A partitioned Berlin was one component of the inner German border. The separation of Berlin divided the city into two zones - a Soviet zone and a Western zone controlled by the United States, Great Britain and France - with the entire city contained within Soviet-controlled East Germany.
} 
Rather than its ability to impede the tide of human movement, the lasting legacy of the Iron Curtain was its capacity to hinder the flow of ideology from one side to the other. Such ideological domination was implemented through the Soviet Union's strategic use of various tools: the regulation and restraint of social and religious movements through its use of Moscow-directed state police forces in satellite countries; the squelching of political diversity and democratic electoral processes; the development and execution of centralized land ownership and economic policies; and, the manipulation of print and radio media. It is the non-material nature of the Iron Curtain's history that is of special interest here. That is, both the actual green line that dominated the separation of Eastern and Western Europe in the early years of the Iron Curtain and the ideological boundary that continued to exist throughout the physical barrier's steady multi-decade hardening. In the end, this ideological barrier became so ingrained and substantive, that its non-material influence and legacy existed well beyond the crumbling of its material remains.

\section{THE IRON CURTAIN - SEPARATION}

The immediate task of the post-World War II Iron Curtain, established by the victors as they divvied their continental spoils, was its provision of an opaque ideological barrier between two distinctly differing and bitterly contested world views, each perspective deemed a mortal threat to the other. East of the boundary line, the Soviet Union now controlled a vast swath of the European continent where they were committed to the implementation of socialist political economy via a totalitarian authority. Across this immaterial divide, the United States and its Western European allies avowed political economic principles endowed upon democratic philosophies of governance and the dogma of profit-driven capitalism. While the control of the flow of humans was an important 
element of the spatial separation between Eastern and Western Europe, any deterrence of human movement primarily existed to serve the much greater goal of impeding the flow of human ideology and culture. While the barrier gradually hardened over the Iron Curtain's first decade with the addition of heavy fencing, checkpoints and a military presence, it was the initial years of its soft existence, when in many areas the boundary was composed primarily of geographic land marks and topographical obstacles, that this line of demarcation resonated most clearly as, fundamentally, an ideological barricade.

The acute threats to everyday survival between the warring factions had mostly abated with the Paris Peace Treaties in 1947. Yet, going forward there remained the possible peril of one side inoculating the other's pure ideology, and, as such, the need for ideological spatial buffering endured. The partition rendered by the Iron Curtain was striking and its dichotomies were evidenced in the significant efforts taken by both factions to fuel and sustain intentional, manufactured perceptions of their particular ideologies. Such were the heightened fears of philosophical contagion that the East attempted to manage this boundary by severely limiting the flow of information, primarily through the state-controlled manipulation of print and radio media, into and out of (as well as within) its sphere of influence. In this way, the impenetrability of the Iron Curtain inhibited the flow of infectious Western ideals into East Europe, as well as promoted the benefits and values of the prodigious Soviet-inspired socialist project at home.

\section{THE IRON CURTAIN - STRUCTURE}

Henk van Houtum (2002) writes that borders exist to "shape a unique and cohesive order" (van Houtum, 126) and the Iron Curtain was a reflection of such a post-war exigency. The Soviet empire was immense, subsuming a vast zone encompassing its 
puppet states along its western border. Where those states interfaced with a democratic and capitalistic Western Europe posed significant issues in terms of quelling chaos and implementing control over a population (with varied cultures) struggling in the aftermath of years of brutal warfare. In the example of the Iron Curtain, the infrastructural elements necessary to create such order along that boundary were supplied in the form of state mechanisms of rigid social and ideological control. The Moscow government bureaucracy enforced strict, hierarchical patterns of delegated authority, centralized land utilization and economic policies, heavy-handed secret state police, and the strict oversight of youth groups and religious organizations as modes of regulating place-making in these spaces that exist at the intersection of "territorial violence... [and] ... collective well-being" (Harris, 101).

Mathijs Pelkmans (2012) describes border zones as functioning in slowing the interface of alien human cultures in order to "... create order out of chaos" (Pelkmans, 270). In the case of the Iron Curtain, rigid controls of the border populations, especially on the Soviet side, serve to promote a steadying of the transition from one cultural milieu to another, or from one superintended by a new totalitarian vision where liberal democratic values prevailed just a handful of years prior. For better or worse, these ideological border zones, as described by Anssi Paasi (1998), allow newly emerging cultures the dynamics necessary, through temporal and spatial compression, to "ultimately [become] reproduced in local everyday life" (Paasi, 670). Edith Sheffer's (2011) description of this phenomenon at the Sonneberg-Neustad margins remains a representative example of the infrastructural elements (Soviet cultural regimentation, topographical obstacles, signage and lexicon, as 
examples) that provide the controls necessary to allowed for manageable transitions in such chaotic environments.

\section{THE IRON CURTAIN - SOCIAL SKIN}

Beyond their ability to shape new order, van Houtum (2002) recognizes that borders also "erase... ambivalent identities" (van Houtum, 126) in zones of cultural in-betweens. Mathijs Pelkmans (2012) describes the role of the Iron Curtain in facilitating the fusion of alien identities into idiosyncratic, multinational citizens at the points of interface along the outer skin of this boundary line. Describing such frontier sectors, Pelkmans depicts these areas as being endowed with the "imaginary and physical permeability" (Pelkmans, 274) that allowed for incongruous populations and their ideologies to touch and intermix with one another in order to initiate the process of coalescence.

Edith Sheffer (2011) provides an ideal lesson of the types of amalgams created in such space. In her analysis of the intra-German Iron Curtain, Sheffer describes the effects of this "wall in the head" (Sheffer, 4) and "invisible 'green border"” (Ibid.: 34) on the villages of Sonneberg and Neustad, age-old neighbors now just on either side of the divide. During the early years of the Iron Curtain, the villages retained many of the shared trade and social institutions they had relied upon for hundreds of years. With time, the villages evolved so that their respective cultures more closely resembled those of typical Sovietbloc and Western societies, while always preserving some semblance of their original ones. With the fall of the Iron Curtain some forty years later, the villages would eventually wish to be comfortably divided again, as villagers in Sonneberg on the eastern side of the ideological boundary had seemingly evolved into Anne Applebaum's vision of Homo sovieticus, while those on the western side claimed their own post-Curtain identities. 


\section{THE IRON CURTAIN - SYMBOLISM}

The Iron Curtain is wrought with symbolic meaning from its conception. Foremost amongst these meanings is the emergence of the imagery of good versus evil. From the perspective of the Western observer, iron as the component 'material' of this boundary line conveys specific messaging. Iron is not only nontransparent, it is also dark, unwieldy and cold - thus, an ideal metaphor, as Winston Churchill (1948) suggests, to illustrate the vast chasm between "civilized society" and "wicked men", or rather an acknowledgement of a fraternal association of Western Europe and the United States aligned against the tyrannical Other of High Stalinism. ${ }^{17}$ It is through such descriptive dichotomous imagery that, for example, "socialist protectionism versus capitalist laissez-faire; and, Soviet repression versus the freedom of democracy" (Pelkmans, 269) is most clearly articulated across multiple cultures and in any dialect. In this way, ideological borders, as social symbols, hold steadfast their consistent ability to regulate boundaries of identity and culture and, thereby, demarcate territorial limits.

Anssi Paasi (1998) and David Ryan (2016) remind us that the interpretations of symbols are contextual and "historically contingent" (Paasi, 679), and, as such, vary based upon the senses and perspectives of the individual interpreter at any given time. So, while the barrier is seen in the late-1940s as a representation of two distinct and successful forms of government, it's likely that a contemporary interpretation of the Iron Curtain is built mostly upon the perceived failures of socialism.

\footnotetext{
${ }^{17}$ The cartoon seen in the appendix (Image 7 - Imagery of the Iron Curtain) highlights such a notion with its suggestion that Eastern Europe cordoned itself off in an attempt to hide its nefarious motives from Winston Churchill, who pried on behalf of free men everywhere.
} 
The hardened components of the Iron Curtain begin to fall in the late-1980s. As the materialities of these walls crumble, they serve as an additional metaphor for the waning ideological differences between the East and West, further highlighting the importance of contemporary interpretations of historic materialities. As van Houtum (2002) writes, the Iron Curtain, like all borders, “symbolize[s] [changing] social practice[s] of spatial differentiation" (van Houtum, 126).

\section{THE IRON CURTAIN - SOCIETAL STATUS QUO}

While the role of maintaining societal status quos was binary in nature (in that the Soviet Union and the West both placed significant strategic interest in accomplishing such a goal), it was in Eastern Europe where the emphasis for doing so was most clearly evident. Joseph Stalin, General Secretary of the Communist Party of the Soviet Union, had been responsible for maintaining the Soviet status quo in the years following the Bolshevik Revolution. Post-World War II, Stalin continues to implement policies favoring the ruling class. Though professing equality across the whole of Russian society through their socialist experiment, in reality the members of the ruling Communist Party, as well as their family and friends, were enriched with an unequal share of power, mobility and wealth. In order to maintain such advantaged social class structures at home, Moscow recreated similar governing architecture in each of the satellite puppet governments under its control. Through such administrative frameworks, Paasi (1998) recognizes that such boundaries are more than "static lines", rather they are "sets of practices and discourses which 'spread' into the whole of society and are not restricted to the border areas" (Paasi, 670). In applying and, subsequently, normalizing intentional patterns of governance and social structure at its borders, Moscow reinforced existing 
hierarchies at home and vice-versa. In this, Stalin found considerable success in maintaining pre-War status quos in Moscow. 


\section{CHAPTER 4 - CONCLUSION}

THE PAST

Walls are a consistent part of the human landscape and have been so for ages. The cognitive machinery and cultural mechanisms that respond to the human need for imagining, constructing and maintaining boundaries are enduring and deeply etched within the neural processors of a brain responsible for coordinating such behavior. The coevolution of cognition and culture, bound by the steady, dynamic pressure of natural selective processes, has culled out essential elements that remain at the foundation of all wall-building endeavors. These elements are described here as an original theory, the $S$ ential Theory of Human Wall-Building, that describes and analyzes the whys of such human efforts. This theory states that humans construct walls in order to provide separation and buffering from real or imagined danger; a retinaculum for the cultivation and implementation of structure and stability in chaotic zones of contact; a social skin that manages and monitors the blending and fusion of different people and their cultures; the expression of symbolic imagery through materialities, as well as non-material lexicon and ideology; and, an intentional mechanism for reifying existing status quos in the wallbuilder's social matrices and hierarchies.

What is clear in this analysis is that such behavior is consistent and plastic through

time and space. The underlying drivers to place obstacles that impede the innate human impulse to be mobile are so resilient as to be consistent across long time spans and, yet, 
flexible enough to be molded into various typologies. The comparative analysis of the early- $2^{\text {nd }}$ century Hadrian's Wall and the mid $-20^{\text {th }}$ century Iron Curtain validates the tenets of the S-ential Theory. Hadrian's Wall is primarily a material structure effecting the slowing of people and goods across a frontier zone, while during its earliest years the Iron Curtain served to principally impede the flow of ideology. Despite these differences and the fact that these walls were erected nearly two millennia apart, the fundamental principles underlying their construction and maintenance are, for all intents and purposes, the same. While the barriers themselves differ considerably in type, the underlying processes are consistent. Hadrian's Wall and the Iron Curtain are simply reflections of the human tendency to consistently control, manage and counteract our instinctive mobility through the construction of barriers. With additional inquiry and comparative analysis, the S-ential Theory will, I argue, remain relevant and verifiable across the panoply of human borders constructed over many thousands of years and across the entire typological spectrum from the physical to the ideological.

\section{THE PRESENT}

Several critical challenges face the human community as we grapple with the apparent acceleration of contemporary wall-building. Foremost among such concerns are the ramifications of the early stages of global climate change, the rise of nation state populism and (the often violent) expression of religious extremism. The most profound of these tests is the existential threat of global climate change. With the onset of significant climatic change already upon us, humans will be compelled to become more mobile as they attempt to escape the environmental stressors of heat and wildly vacillating weather patterns. In addition, the demographic realities of the shrinking access to a waning pool of 
natural resources, such as clean water and arable land, results in an intensified competition for any given finite resource. Fewer opportunities for employment, in the face of expanding human populations and the implementation of artificial intelligence, compound such pressures and raise vital questions regarding future economic sustainability. These difficulties are further augmented by a widening global economic chasm between the rich and poor, as wealth incrementally concentrates into the hands of the relatively few able to successfully manipulate systems of exploitive capitalism or master the skill of often malfeasant financial systems gamed to advantage the global elite. The end result of such constraints is that humans flee toward regions where marginally improved opportunities are perceived to exist. Such mobility is conspicuous in the mass movements seen today as large human populations attempt to escape conflict and economic unsustainability in the Middle East and northern Africa, as well as fleeing unemployment, narco-gang violence and climate change in Central and South America and Mexico.

In this current milieu, the economic haves, battling the economic have nots in order to protect the limited resources they believe to be manifestly theirs, identify the have nots as Others. Compounding such pressures, blatant Eurocentrism is expressed as a mostly white, and often Christian, hegemony that attempts to dominate people of color. As barriers to human flow are placed in southern Europe, the Mediterranean and the southwestern United States, they are done so in order to manage borders in such a way as to defend economic priorities and promote nationalist agendas. Radicalized ideology in the form of nationalist and religious extremism has always been reflective of social systems engineered to favor cultural elites. 
Today, economic disparity, diminishing resources and climate change are the diseases threatening human existence, while rising nationalism and the building of borders are their symptoms. Additionally, existing social disequilibrium is magnified even further through the real-time transmission of information via the internet and social media platforms. An ebbing pool of available financial and natural resources, rising nationalism and the acceleration of religious conservatism lend themselves to human wall-building endeavors. These issues make walls ideal vessels through which the political elite can express the various tenets of the S-ential Theory of Human Wall-Building. Just as in the past, walls continue to be utilized to separate and control us, provide intentional symbolic messaging and reinforce the status quo amongst the ruling classes.

\title{
THE FUTURE
}

\author{
No man is an island, \\ entire of itself; \\ every man is a piece of the continent, \\ a part of the main. \\ If a clod be washed away by the sea, \\ Europe is the less, \\ as well as if a promontory were, \\ as well as if a manor of thy friend's \\ or of thine own were. \\ Any man's death diminishes me, \\ because I am involved in mankind; \\ and therefore never send to know for whom the bell tolls; \\ it tolls for thee. \\ John Donne \\ From Meditation 17, 1623
}

The basic ingredients of wall-building are deeply rooted in the evolutionary processes designed to better insure the near-term survival and long-term propagation of the human species. As such, the propensity to construct barriers is certainly semi-fixed, at least in the sense that generational change is difficult to visualize much less to effectuate. No doubt, then, that humans will be compelled to continue to construct physical and 
ideological barriers into the foreseeable future. But important questions linger as we attempt to interpret the meanings and functions of walls going forward. For example, when do walls become meaningless? What unfamiliar challenges will arise that amplify the need for additional physical or ideological buffering between us? What as yet unknown controversies will expand the sounding of the alarms that harken a need for the augmentation of existing border structures? As new types of walls emerge and become increasingly complex, will there be opportunities to change the way in which borders are imagined and managed as social institutions? Could the internet and social media provide further points of human linkage that provide groups the clarity and perspective necessary to properly attend to their global responsibilities?

George Harris (2010), the American-centric geopolitical strategist, argues that human behavior has always been cyclical and, therefore, is inherently repetitive in nature. That is, even in the face of significantly varied decision-making data points, humans will generally make similar choices. What will it take to break this cycle as it relates to the chronicity of human wall-building? As the human story unfolds, the potential for conflict and suffering will become steadily less regional and more global in nature, extending the ramifications of decision-making well beyond demarcated borders. For instance, issues of climate change and environmental degradation are, in many ways, borderless issues. Spiraling thermometers, diminishing water quality and pandemic disease affect us all as these concerns cross traditional borders at will. Therefore, solving global problems via nation-state bureaucracies beholden to vested national interests will be arduous, at best. Global solutions to global dilemmas are required and, ultimately, will be demanded. 
Breaking Harris' cycle may only be possible as humans recognize the realities of existential threats. Only broad mandates, developed through processes of political pragmatism in which global responsibilities and basic national priorities are both acknowledged, will suffice to address such convoluted concerns. In this regard, the function of walls to provide a social skin for the interfacing and connecting of varied cultures, each with its own perspective and self-interests, will be especially relevant. What seems certain is that the key to a future alongside barriers will be the assumption that not all walls need to be deconstructed. Instead, it will be imperative to remove walls that are fundamentally unjust while managing existing barriers in such a way as to defend only the most basic national priorities, and promote a just, more equitable and pluralistic society, while, simultaneously, beginning to find real solutions to global quandaries. Whether a short-sighted human species is ready for such a Herculean task remains to be seen. 


\section{REFERENCES}

Applebaum, A. (2012). Iron Curtain: The crushing of Eastern Europe, 1944-1956. New York: Anchor Books.

Antón, S. C., \& Swisher, III, C. C. (2004). Early Dispersals of Homo from Africa. In the Annual Review of Anthropology, 33, 271-296.

Auyero, J. (2012). Patients of the state: The politics of waiting in Argentina. Duke University Press.

Bellwood, P. (2013). The relevance and reality of ancient migration. In First migrants: Ancient migration in global perspective, 1-16. John Wiley \& Sons.

Bruce, J. C., \& Breeze, D. J. (2006). Handbook to the Roman wall. Society of antiquaries of Newcastle upon Tyne.

Breeze, D. J., \& Dobson, B. (2000). Hadrian's Wall. London: Penguin Books.

Beyin, A. (2015). Human origins, dispersal and associated environments: An African perspective. Ethnology, ethnography and cultural anthropology. In Encyclopedia of life support systems (EOLSS). Eds. UNESCO \& EOLSS Joint Committee. Developed under the auspices of the UNESCO. EOLSS Publishers.

Churchill, R. S. (1948). The Sinews of Peace: Post-war speeches of Winston S. Churchill. London: Cassells.

Connah, G. (2000). Contained communities in tropical Africa. In City Walls: The urban enceinte in global perspective. Oxford University Press.

Cresswell, T. (2001). The production of mobilities. New Formations, 43, 11-25.

Cutting, M. (2006). More than one way to study a building: Approaches to prehistoric household and settlement space. Oxford Journal of Archaeology, 25(3), 225-246.

De Atley, S. P., \& Findlow, F. J. (1984). Exploring the limits: Frontiers and boundaries in prehistory (Vol. 223). BAR.

De Genova, N., \& Nathalie Peutz (Eds.). (2010). Introduction. The deportation regime: Sovereignty, space, and the freedom of movement. Duke University Press. 
Diamond, J. (1997). Guns, germs, and steel: The fates of human societies. New York: W. W. Norton \& Company.

Donald, M. (1991). Origins of the modern mind: Three stages in the evolution of Culture and cognition. Harvard University Press.

Farge, A. (2013). The allure of the archives. Yale University Press.

Forsberg, T. (2003). The ground without foundation: Territory as a social construct. Geopolitics, 8(2), 7-24.

Friedman, G. (2010). The next 100 years: A forecast for the 21 st century. New York: Anchor Books.

Flusser, V. (2003). The Freedom of Migrant: Objections to Nationalism. University of Illinois Press.

Goldsworthy, A. (2018). Hadrian's Wall. New York: Basic Books.

Haidt, J. (2007). The new synthesis in moral psychology. Science, 316(5827), 9981002.

Haidt, J. (2012). The righteous mind: Why good people are divided by politics and religion. New York: Vintage.

Harari, Y. N. (2015). Sapiens: A brief history of humankind. New York: HarperCollins.

Harris, S. (2010). The moral landscape: How science can determine human values. New York: Free Press.

Haynes, I. (2014). Hadrian's Wall: Life on the Roman frontier. [FutureLearn on-line course]. Retrieved from https://www.futurelearn.com/courses/hadrians-wall

Howe, N. (2005). Anglo-Saxon England and the postcolonial void. Postcolonial Approaches to the European Middle Ages, 54, 25-47.

Ingold, T. (2005). Comments on Christopher Tilley: The materiality of stone: Explorations in landscape phenomenology. Oxford: Berg, 2004. Norwegian Archaeological Review, 38(2), 122-129.

Jaubert, J. et al. (2016). Early Neanderthal constructions deep in Bruniquel Cave in southwestern France. Nature, 534, 111-114.

Jensen, A. (2011). Mobility, space and power: On the multiplicities of seeing mobility. Mobilities, 6(2), 255-271. 
Jones, R. (2016). Violent borders: Refugees and the right to move. London: Verso.

Kagan, R. L. (2000). A world without walls: City and town in colonial Spanish America. City Walls: The Urban Enceinte in Global Perspective, 117-152.

Kuhn, S. L. et al. (2009). The early Upper Paleolithic occupations at Üçağızlı Cave (Hatay, Turkey). Journal of Human Evolution, 56(2), 87-113.

Kuijt, I. (2000). People and space in early agricultural villages: Exploring daily lives, community size, and architecture in the Late Pre-Pottery Neolithic. Journal of Anthropological Archaeology, 19(1), 75-102.

Lobell, J. A. (2017). The wall at the end of the empire. Archaeology, 70(3), 26-35.

Low, S. M. (2009). Towards an anthropological theory of space and place. Semiotica, 2009(175), 21-37.

Mellars, P. (2006). Going east: New genetic and archaeological perspectives on the modern human colonization of Eurasia. Science, 313(5788), 796-800.

Muir, R. (2000). The new reading the landscape: Fieldwork in landscape history. University of Exeter Press.

Nesbitt, C., \& Tolia-Kelly, D. (2009). Hadrian's Wall: Embodied archaeologies of the linear monument. Journal of Social Archaeology, 9(3), 368-390.

Newman, D. (2003). On borders and power: A theoretical framework. Journal of Borderlands Studies, 18(1), 13-25.

Paasi, A. (1998). Boundaries as social processes: Territoriality in the world of flows. Geopolitics, 3(1), 69-88.

Pelkmans, M. (2012). Chaos and order along the (former) Iron Curtain. A Companion to Border Studies, 269-282.

Peteet, J. (2017). Space and mobility in Palestine. Indiana University Press.

Peteet, J. (2005). Landscape of hope and despair: Palestinian refugee camps. University of Pennsylvania Press.

Pinker, S. (2010). The cognitive niche: Coevolution of intelligence, sociality, and language. Proceedings of the National Academy of Sciences, 107(Supplement 2), 8993-8999. 
Reyerson, K. L. (2000). Medieval walled space: Urban development vs. defense. In City walls: the urban enceinte in global perspective, 4, 88-116. Cambridge University Press.

Richerson, P. J., \& Boyd, R. (1998). The evolution of human ultrasociality. Indoctrinability, ideology, and warfare: Evolutionary perspectives, 71-95.

Ryan, D. (2016). Curtains, culture and 'collective' memory. Journal of Transatlantic Studies, 14(4), 401-415.

Sack, R. D. (1986). Human territoriality: Its theory and history (Vol. 7). Cambridge University Press Archive.

Sassen, S. (2014). Expulsions: Brutality and complexity in the global economy. Harvard University Press.

Sanyal, R. (2014). Urbanizing refuge: Interrogating spaces of displacement. International Journal of Urban and Regional Research, 38(2), 558-72.

Sheffer, E. (2011). Burned Bridge: How East and West Germans made the Iron Curtain. Oxford University Press.

Shryock, A., Smail, D. L., Earle, T. (2011). Deep history: The architecture of past and present. University of California Press.

Singleton, T. A. (2001). Slavery and spatial dialectics on Cuban coffee plantations. World Archaeology, 33(1), 98-114.

Sterling, B. L. (2009). Hadrian's Wall: Rome's foremost frontier fortification. In Do good fences make good neighbors?: What history teaches us about strategic barriers and international security (pp. 64-105). Washington, D.C.: Georgetown University Press.

Stiner, M. C. (2002). Carnivory, coevolution, and the geographic spread of the genus Homo. Journal of Archaeological Research, 10(1), 1-63.

Suddendorf, T. (2013). The gap: The science of what separates us from other animals. New York: Basic Books.

Torpey, J. (1998). Coming and going: On the state monopolization of the legitimate "means of movement". Sociological Theory, 16(3), 239-259.

Tracy, J. D. (Ed.). (2000). City walls: The urban enceinte in global perspective (Vol. 4). Cambridge University Press. 
Trout, P. A. (2011). Deadly powers: Animal predators and the mythic imagination. Amherst, NY: Prometheus.

Van Houtum, H., \& Van Naerssen, T. (2002). Bordering, ordering and othering. Tijdschrift voor economische en sociale geografie, 93(2), 125-136.

Watkins, T. (2004). Building houses, framing concepts, constructing worlds. Paléorient, $5-23$.

Witcher, R., Tolia-Kelly, D. P., \& Hingley, R. (2010). Archaeologies of landscape: Excavating the materialities of Hadrian's Wall. Journal of Material Culture, 15(1), 105-128.

Wobst, H. M. (1974). Boundary conditions for Paleolithic social systems: A simulation approach. American Antiquity, 39(2Part1), 147-178.

Zhang, D., Dong, G., Wang, H., Ren, X., Qiang, M., \& Chen, F. (2016). History and possible mechanisms of prehistoric human migration to the Tibetan Plateau. Science China Earth Sciences, 59(9), 1765-1778. 


\section{APPENDIX}

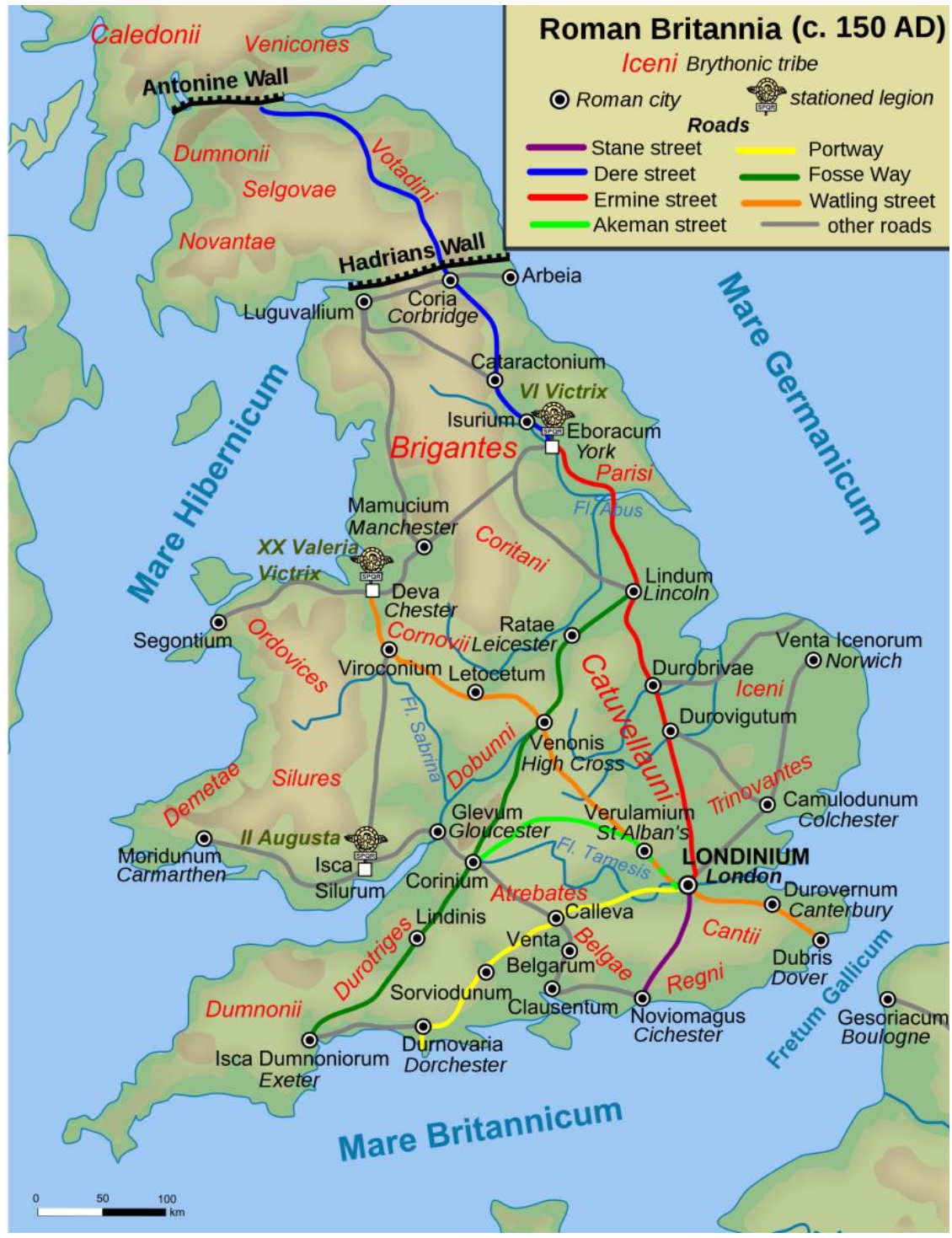

\section{Image 1 - Roman Britannia}

The map depicts the extent of the Roman occupation of Britannia at the time of construction of Hadrian's Wall, as well a listing of the major Celtic tribes co-occupying the island.

Credit: Nacu, Andrei. 2012. "Map of Roman Britain, 150 A.D.” Retrieved 15 September 2018

(https://www.ancient.eu/image/575/map-of-roman-britain-150-ad/) 


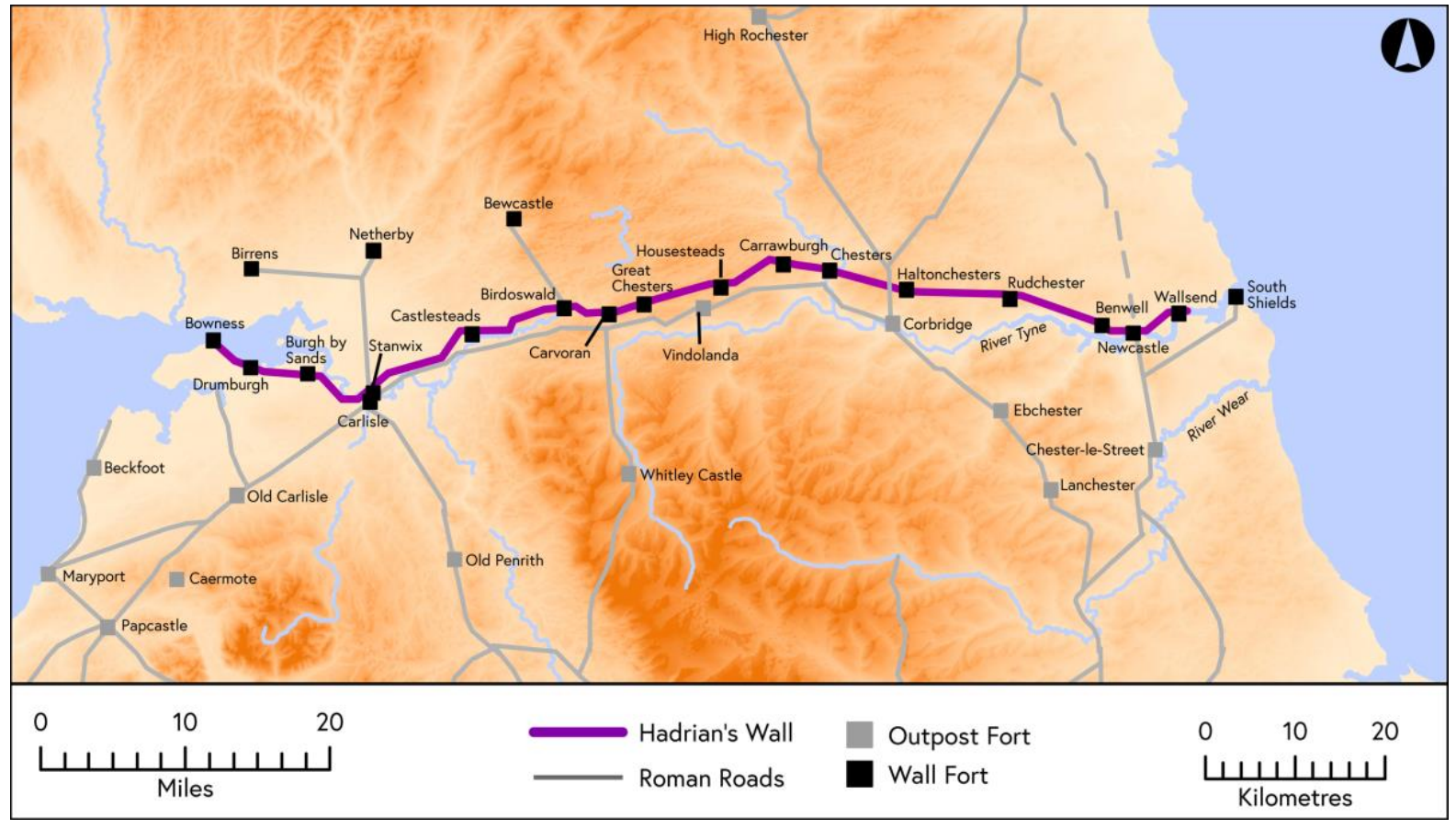

\section{Image 2 - Route of Hadrian's Wall}

Note the associated wall forts and outposts along the entire length of the wall from South Shields in the east to Bowness in the west. Cumbrian outposts protected Roman Britannia from invasion from the sea.

Credit: Retrieved 15 September 2018 (https://www.futurelearn.com/courses/hadrians-wall/0/steps/5101) 


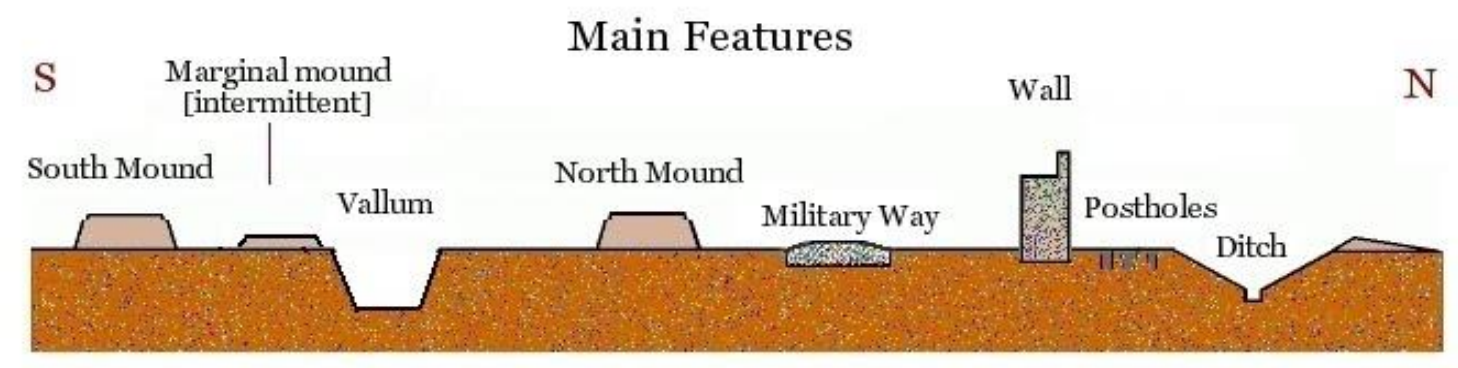

Image 3 - Cross section schematic analysis of the components of Hadrian's Wall

The combination of mounds and vallum on the southern side of the wall served not only in slowing the ingress of any invading force from the north, but, as importantly, slowed the egress home of any invading force that successfully made its way into Roman territory.

Credit: "Schematic section of the main features of the Vallum and Wall". Theoretical Structural Archaeology. Retrieved 15 September 2018 (structuralarchaeology.blogspot.com/2010/11/40-reverseengineering-vallum.htm)

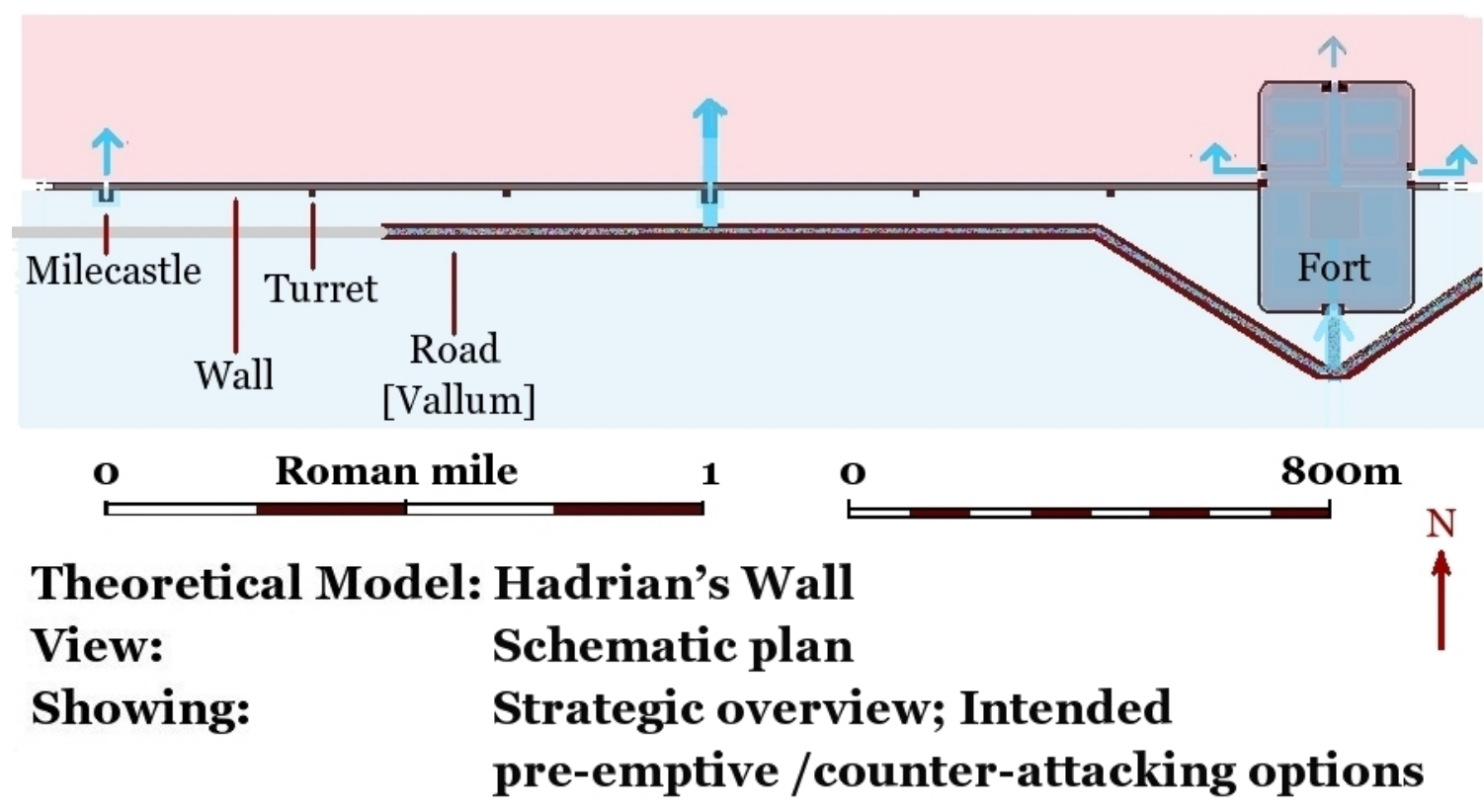

Image 4 - Aerial schematic view of Hadrian's Wall

Note the service road running the length of Hadrian's Wall just to its south. This transportation route served to facilitate both supplying troops along the Wall's length, as well as allowing those troops to move laterally as quickly as possible.

Credit: “Theoretical Model: Hadrian's Wall". Theoretical Structural Archaeology. Retrieved 15 September 2018 (http://structuralarchaeology.blogspot.com/2012/01/hadrians-first-wall-part-3-of-3.html) 


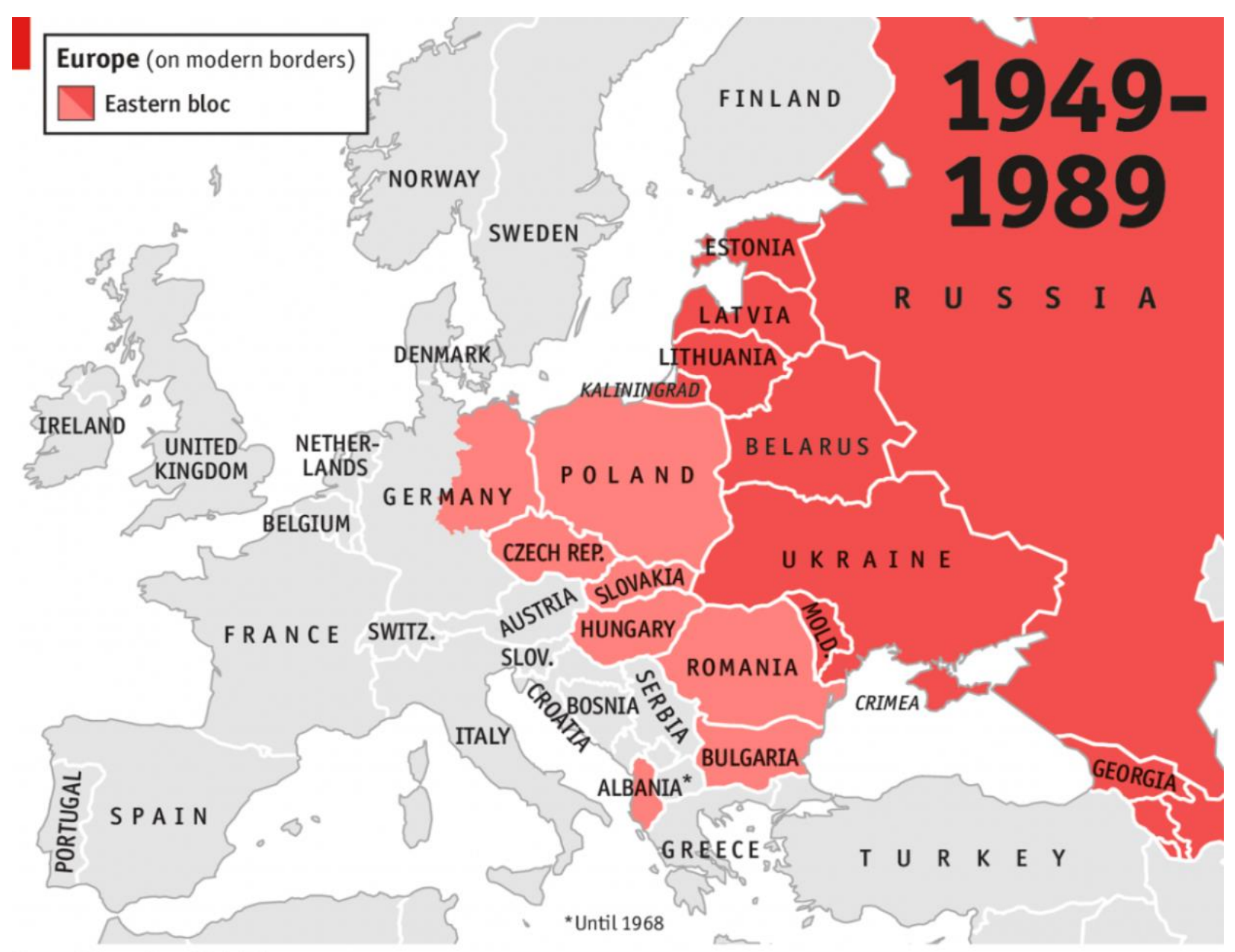

Economist.com/graphicdetail

\section{Image 5 - The Iron Curtain}

This map highlights Soviet-bloc countries behind the Iron Curtain.

Credit: "Map of Cold War Europe 1949-1989 borders of USSR and Iron Curtain" Hammer and Scythe: The Ebb and Flow of Russian/Soviet Influence 20 March 2014 in The Economist. Retrieved 15 September 2018 (https://www.economist.com/graphic-detail/2014/03/20/hammer-and-scythe) 


\section{Burned Bridge on Germany's Iron Curtain}

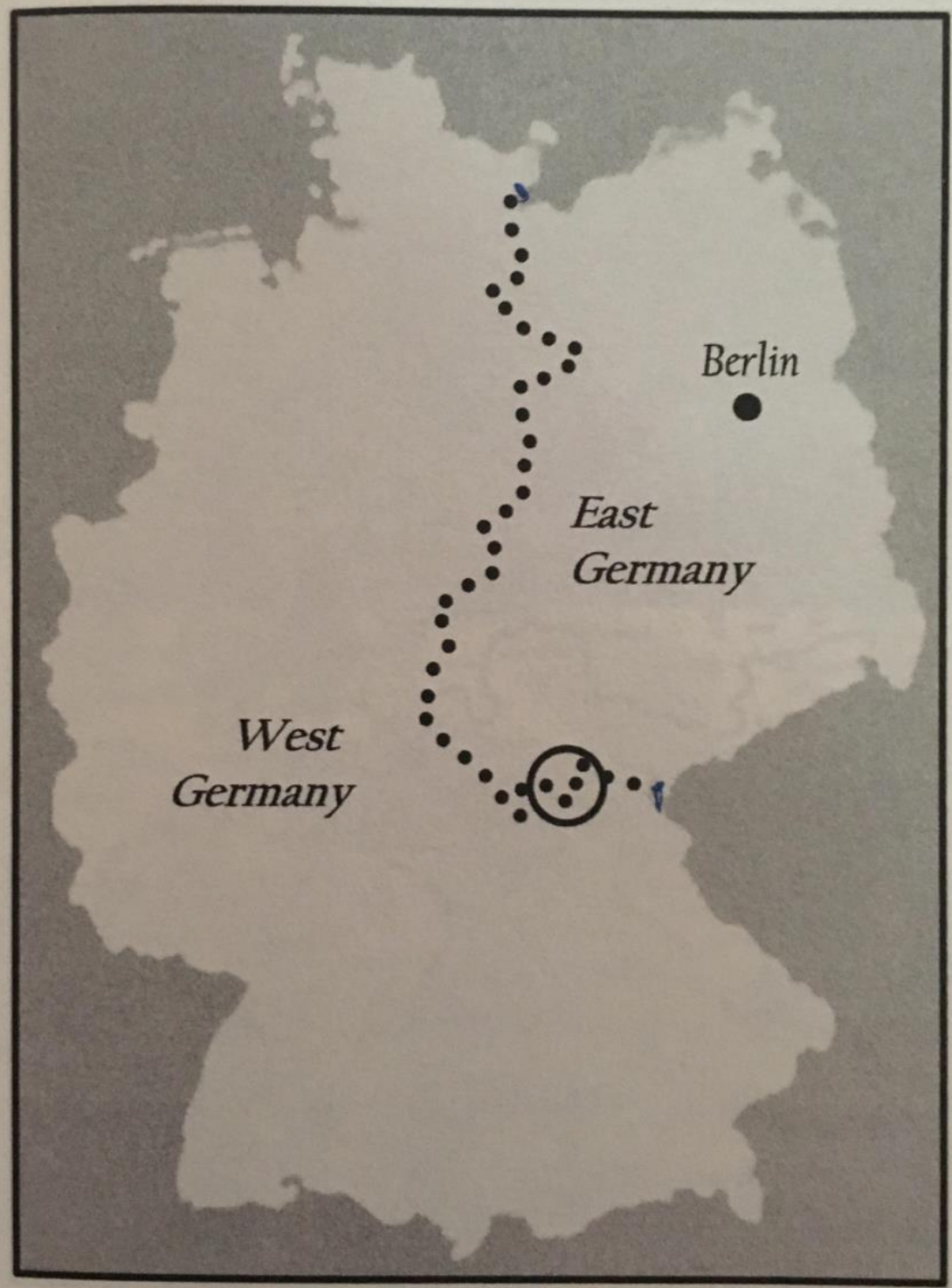

\section{Image 6 - The Inner Iron Curtain}

This illustration shows the inner Iron Curtain dividing Germany in two. Note that the entirety of Berlin both East Berlin and West Berlin - lay within the eastern bloc. The circle identifies the location of Burned Bridge separating the sister villages of Sonneberg and Neustadt.

Credit: [The Inner-German Iron Curtain. Map]. Retrieved from Sheffer, Edith. Burned Bridge: How East and West Germans made the Iron Curtain. 2011. Oxford University Press. 


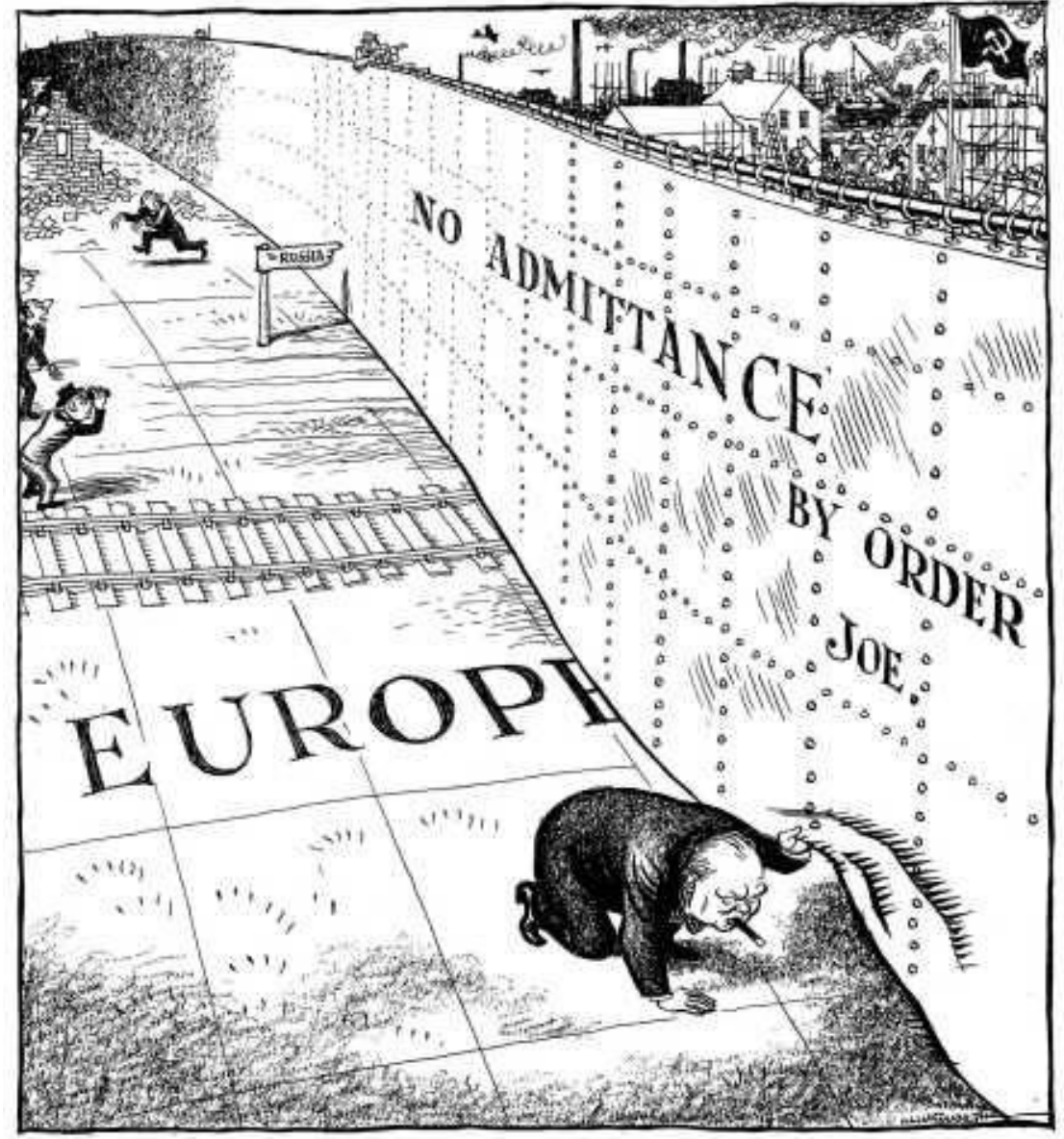

\section{Image 7 - Imagery of the Iron Curtain}

The ideological border of the Iron Curtain was rich in imagery and symbolism.

Credit: Illingworth, Leslie G. 6 March 1946. "Peep Under the Iron Curtain" in The Daily Mail. Retrieved 15 September 2018 from the British Cartoon Archive

(https://archive.cartoons.ac.uk/Record.aspx?src=CalmView.Catalog\&id=ILW1059) 


\title{
CURRICULUM VITAE
}

\author{
Timothy A. Heine, MD \\ 240 South Peterson Avenue \\ Louisville, KY 40206 \\ 502-418-8309 \\ hypnos717@gmail.com
}

\section{EDUCATION}

Graduate Program, Department of Anthropology, University of Louisville, Louisville, KY, 2014-current

MD, University of Louisville, Louisville, KY, 1988

BS, University of Kentucky, Lexington, KY, 1984

MEDICAL TRAINING

NAPE Executive Fellow, Transesophageal Echocardiography, University of Utah, Salt Lake City, UT, 2006

Chief Resident, Anesthesiology, Duke University, Durham, NC, 1995-96

Resident, Anesthesiology, Duke University, Durham, NC, 1993-1995

Resident, General Surgery, Methodist Hospital, Indianapolis, IN, 1989-1990

Intern, Internal Medicine, University of Louisville, Louisville, KY, 1988-1989

PROFESSIONAL EXPERIENCE

Independent Contractor, Louis ville, KY, 2018-current

Partner, The Lazarus Group, LLC, Louisville, KY, 2016-2018

Partner, One Anesthesia, PLLC, Louisville, KY, 2014-2016

Partner, Anesthesia Associates of Louisville, PSC, Louis ville, KY, 2000-2014

Associate, Anesthesia Associates of Louisville, PSC, Louisville, KY, 1998-2000

Faculty, Duke University Medical Center, Durham, NC, 1996-98

Coordinator, Emergency Services, Mercy Hospital, Elwood, IN, 1990-1993

\section{LEADERSHIP POSITIONS}

Founding Director, One Management Services Company, 2012-14

Founding Vice Chairman, Ohio River Valley Associates, Louisville, KY, 2012-13

Chairman, Ohio River Valley Associates, Louisville, KY, 2013-14

Founding Director, One Anesthesia, PLLC, Louisville, KY, 2014

Merger Committee, One Anesthesia, PLLC, Louisville, KY, 2012-14

Vice President, Anesthesia Associates of Louisville, PSC, Louis ville, KY, 2013-14

President, Anesthesia Associates of Louisville, PSC, Louisville, KY, 2010-13

Director, Anesthesia Associates of Louisville, PSC, Louisville, KY, 2001-05, 2009-14 


\section{HONORS}

Top Doctor, Anesthesiology, Louisville Magazine, 2009, 2010, 2012, 2015-2017

Robert N. Sladen Teacher of the Year Award, Dept. of Anesthesiology, Duke University, Durham, NC 1997-98

VA Teaching Award, Dept. of Anesthesiology, Duke University, Durham, NC, 1996-97 Chief Resident, Anesthesiology, Duke University, Durham, NC, 1995-96

Professional \& ACADEMIC AFFILIATIONS

Archaeological Institute of America - Kentucky Chapter, 2016-current

Diplomate, American Board of Anesthesiology, 1997-current

\section{COMMUNITY ENDEAVORS}

ACLU-KY Board of Directors, Louisville, KY, 2019-current

Executive Committee, Clifton Center, Louisville, KY, 2006-15

President, Board of Directors, Clifton Center, Louisville, KY, 2006-08

Director, Clifton Center, Louisville, KY, 2002-15 